\begin{abstract}
UNIVERSIDADE DE SÃO PAULO
FFCLRP - DEPARTAMENTO DE FÍSICA

PÓS GRADUAÇÃo EM FíSICA APLICADA À MEDICINA E BIOLOGIA
\end{abstract}

MARCELA FÉLIX CHAVES FERREIRA

IMPLEMENTAÇÃO DE UMA ANÁLISE COMPUTADORIZADA DA CURVA DE EMISSÃO TERMOLUMINESCENTE E APLICAÇÃO EM DOSIMETRIA CLÍNICA 


\title{
IMPLEMENTAÇÃO DE UMA ANÁLISE COMPUTADORIZADA DA CURVA DE EMISSÃO TERMOLUMINESCENTE E APLICAÇÃO EM DOSIMETRIA CLÍNICA
}
Dissertação apresentada à Faculdade de Filosofia, Ciências e Letras de Ribeirão Preto da Universidade de São Paulo como parte das exigências para a obtenção do título de Mestre em Ciências.

Área de Concentração: Física Aplicada à Medicina e Biologia

Orientador: Prof. Dr. Alessandro Martins da Costa

\begin{abstract}
UNIVERSIDADE DE SÃO PAULO
FACULdADE DE FILOSOFIA, CIÊNCIAS E LETRAS DE RIBEIRÃo PRETO FFCLRP
\end{abstract}

Ribeirão Preto - SP 


\section{FICHA CATALOGRÁFICA}

\section{Ferreira, Marcela Felix Chaves}

Implementação De Uma Análise Computadorizada Da Curva De Emissão Termoluminescente E Aplicação Em Dosimetria Clínica. Ribeirão Preto, 2017.

Dissertação de Mestrado, apresentada à Faculdade de Filosofia, Ciências e Letras de Ribeirão Preto/USP. Área de concentração: Física Aplicada à Medicina e Biologia.

Orientador: Costa, Alessandro Martins da

1. Dosimetria. 2. Termoluminescência. 3. Análise da Curva de Emissão 


\section{FOLHA DE APROVAÇÃO}

Marcela Félix Chaves Ferreira

Implementação De Uma Análise Computadorizada Da Curva De Emissão Termoluminescente E Aplicação Em Dosimetria Clínica.

Dissertação apresentada à Faculdade de Filosofia, Ciências e Letras de Ribeirão Preto da Universidade de São Paulo para a obtenção do título de mestre.

Área de Concentração: Física Aplicada à Medicina e Biologia

Aprovada em: $\underline{28} / \underline{02} / \underline{2018}$.

BANCA EXAMINADORA

Prof. Dr. Éder José Guidelli

Doutor pelo Departamento de Física desta Faculdade

Dra. Felícia Del Gallo Rocha

Doutora pela Comissão Nacional de Energia Nuclear e Pesquisadora no Centro Tecnológico da Marinha em São Paulo

Dr. José Carlos Borges

Doutor e Assistente Técnico do Centro de Ensaios e Pesquisas em Metrologia 
"No meio da confusão, encontre a simplicidade.

A partir da discórdia, encontre a harmonia.

No meio da dificuldade reside a oportunidade. "

Albert Einstein 


\section{Dedicatória}

Dedico este trabalho aos meus pais, Hélcio e Claudia, por nunca medirem esforços para me proporcionar uma educação de qualidade e sempre me incentivaram a persistir mesmo nos momentos difíceis; à minha irmã, Gabriela, por me inspirar a ter dedicação e foco todos os dias; e ao meu marido, André, por todo o seu amor, apoio e compreensão. 


\section{Agradecimentos}

Os meus sinceros agradecimentos aos pais, Hélcio e Cláudia, que sempre acreditaram que eu era capaz de chegar onde eu quiser, que me ensinaram o significado de persistir para chegar a um objetivo e me apoiaram nos momentos mais difíceis, e à minha irmã, que me inspira com a sua dedicação e foco em busca de seus objetivos.

Minha gratidão também ao meu marido, André, que ao longo de todo o nosso relacionamento, se tornou meu parceiro e meu alicerce, me ajudando, e incentivando em todos os momentos da minha vida. Obrigada pela compreensão e por tornar os momentos árduos mais prazerosos para mim.

Gostaria de agradecer ao meu orientador, prof. Alessandro, por ter paciência em me ensinar e orientar em todas as etapas desse trabalho. À Cassiana por me ajudar no laboratório para o desenvolvimento das atividades. Aos professores do curso de pós-graduação em Física Aplicada à Medicina e Biologia que contribuíram para a minha formação.

Meus agradecimentos às minhas amigas Daiane, Lívia e Jéssica, pelo suporte e por sempre se preocuparem comigo mesmo longe. Aos colegas de laboratório, Leonardo, Beatriz, Júlio, Matheus e Michel, por me auxiliarem nos momentos em que eu precisei.

Gostaria de agradecer à CAPES pelo apoio financeiro que permitiu a realização desse trabalho, e à Universidade de São Paulo pela oportunidade e credibilidade. 


\section{Resumo}

Nas décadas de 1960 e 1970, as primeiras investigações de dosímetros termoluminescentes (TLD), especificamente, os picos dosimétricos, rapidamente revelaram um número surpreendente de fenômenos que poderiam estar diretamente relacionados à densidade de ionização.

Um pouco mais tarde, nos anos 80 e no início dos anos 90, a radiação aparentemente desconectada induziu fenômenos que foram descobertos em outros sistemas baseados em fluoreto de lítio (LiF). A última década, no entanto, testemunhou o surgimento de vários modelos, encabeçado através de uma compreensão mais profunda dos mecanismos TL subjacentes, bem como na modelagem micro dosimétrica e especificamente desenvolvida para explicar fenômenos de densidade de ionização.

Muitas aplicações em radioterapia fornecem níveis de dose de radiação superiores a 1 Gy, porém em radiodiagnóstico estão na faixa de alguns mGy, e níveis muito altos de precisão são necessárias para promover o tratamento ideal. Isto exige uma atenção muito cuidadosa aos protocolos de medição altamente detalhados, bem como à calibração demorada de todos os TLDs para corrigir a não-linearidade da resposta à dose.

Essas propriedades podem variar de lote para lote e também podem ser uma função da exposição à radiação, do aquecimento e histórico de manuseio. Deste modo, mesmo com excelentes avanços nos estudos do TLD com relação aos tratamentos térmicos e às formas de análise da curva de emissão TL, é necessário continuar os estudos a fim de possibilitar uma melhor utilização desta técnica na clínica.

Uma análise computadorizada da curva de emissão (CGCA - do inglês, computadorized glow curve analisys) foi implementada utilizando dados provenientes do software WinREMS de dosímetros TL que absorvem e armazenam a energia da radiação ionizante, reemitida na forma de fóton na região do ultravioleta visível. A luz emitida é, então, detectada por uma fotomultiplicadora e correlacionada à dose absorvida recebida pelo material. Os picos de emissão foram ajustados por meio de um algoritmo no programa MATLAB adotando-se o modelo de cinética de primeira ordem. 
O material testado foi o LiF:Mg,Ti (fluoreto de lítio dopado com magnésio e titânio) da marca Harshaw e a qualidade do ajuste foi determinada por um parâmetro chamado figura de mérito (FOM - do inglês, figure of merit). O menor FOM obtido para o grupo de dosímetros foi de $1,04 \%$ e o maior foi de $9,79 \%$.

Também foi avaliada a dose mínima detectável, utilizando o parâmetro que apresentou melhor desempenho, segundo a homogeneidade do grupo de dosímetros. O valor médio de dose mínima apresentado foi $28 \mu \mathrm{Gy}$. Os resultados de reprodutibilidade, índice de variabilidade do detector (DVI - do inglês, device variability index) foi 14,01 \%, que pode ser explicado pelo alto número de dosímetros no lote.

Então, com a diminuição do tempo de preparo do dosímetro e com a análise computadorizada da curva de emissão, a utilização clínica do TLD torna-se mais viável, visto que não houve interferência na sensibilidade do dosímetro. Apesar de a reprodutibilidade ter sido a cima do esperado, é indicado uma correção individual para cada dosímetro e o descarte daqueles que apresentarem valores mais discrepantes comparado ao lote. 


\section{Abstract}

In the decades of 1960 and 1970, the first investigations of termoluminescentes dosimeters (TLD), specifically, the dosimetric peaks quickly revealed a surprising number of phenomena that could be directly related to the density of ionization.

A little later, in the years 80 and 90 at the beginning of the year, seemingly disconnected radiation induced phenomena were discovered on other systems based on lithium fluoride (LiF). The last decade, however, has witnessed the emergence of several models, spearheaded through a deeper understanding of the underlying TL mechanisms as well as in modeling specifically developed for microdosimetric and explain phenomena of ionization density.

Many applications in radiation oncology provide levels of radiation dose in excess of 1 Gy, however in diagnostic radiology are in the range of a few mGy, and very high levels of precision are necessary to promote the ideal treatment. This requires careful attention to the highly detailed measurement protocols, as well as the time-consuming calibration of all TLDs to correct the non-linearity of dose-response.

These properties can vary from batch to batch, and can also be a function of exposure to radiation, heating and handling history. In this way, even with excellent advances in the studies of the TLD for the heat treatment and the ways of issuing TL curve analysis, it is necessary to continue studies in order to enable a better use of this technique in the clinic.

A computerized analysis of the emission curve (CGCA - computadorized glow curve analysis) was implemented using data from the WinREMS software of TL dosimeters that absorb and store energy from ionizing radiation, reissued in the form of photon in the visible ultraviolet. The light emitted is then detected by a photomultiplier and correlated to the absorbed dose received by the material. The emission peaks were adjusted by means of an algorithm in MATLAB program by adopting the model of first-order kinetics.

The material tested was the LiF: Mg, Ti (lithium fluoride doped with magnesium and titanium) brand Harshaw and the quality of the fit was determined by a parameter called figure of merit (FOM- figure of merit). The smallest FOM obtained for the group of dosimeters was $1.04 \%$ and the highest was $9.79 \%$. 
Also minimum detectable dose was evaluated, using the parameter that showed better performance, according to the homogeneity of the Group of dosimeters. The average value of minimum dose presented was $28 \mu \mathrm{Gy}$. The results of reproducibility, index of variability of the detector (DVI-English, device variability index) was 14.01\%, which can be explained by the high number of dosimeters in the batch.

Then, with the decrease in the time of preparation of the dosimeter and the computerized analysis of the emission curve, the clinical use of the TLD becomes more viable, since there was no interference on sensitivity of the dosimeter. Although the reproducibility have been above expectations, indicated a single correction for each badge and the disposal of those who submit more discrepant values compared to the batch. 


\section{Lista de Figuras}

Figura 01 - Modelo de Bandas para níveis de energia.

Figura 02 - Diagrama de nível de energia de um material TL.[13].

Figura 03 - Curva de emissão TL típica de um dosímetro utilizando a cinética de primeira ordem[17].

Figura 04 - Curva de emissão típica do LiF:Mg,Ti mostrando a curva original e os picos dissociados após a deconvolução[18].

Figura 04 - Sistema dosimétrico simplificado [26].

Figura 05 - (a) Leitora Harshaw, modelo 3500; (b) Dosímetros TL de LiF:Mg,Ti e pinça para manipulação dos dosímetros

Figura 06 - Espectros de emissão TL do sinal de fundo dos dosímetros: (a) 04; (b) 05; (c)10; e (d) 13 35

Figura 07 - Espectros de emissão TL do sinal de fundo dos dosímetros: (a)27; (b)49; (c)55; (d)61; (e)79; e (f)90 36

Figura 09 - Espectro de emissão TL dos dosímetros de LiF:Mg,Ti irradiados à 8,084 mGy com uma fonte de ${ }^{137} \mathrm{Cs}$ de energia de $661,7 \mathrm{keV}$, cujo parâmetro FOM 1,042\% e é o menor do grupo 


\section{Lista de Tabelas}

Tabela 01 - Análise do sinal de fundo por meio do valor médio $\overline{\mathrm{M}_{0}}$ e do desvio padrão $\left(\sigma_{B G}\right)$

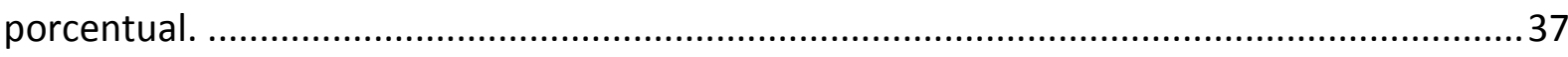

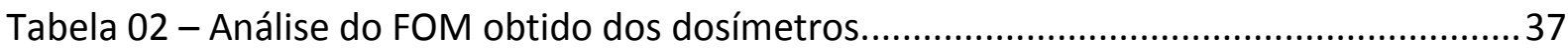

Tabela 03 - Análise do desvio padrão porcentual a partir da análise do valor médio, da intensidade do pico principal antes e depois de realizada a deconvolução pelo método do

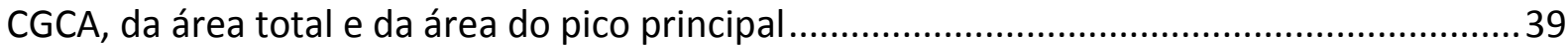

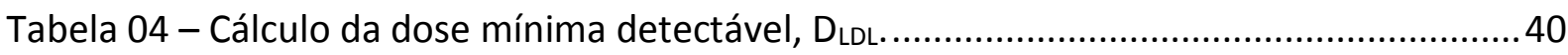

Tabela 05 - Cálculo do Índice de Variabilidade do Sistema (SVI). ........................................40

Tabela 06 - Cálculo do Índice de Variabilidade do Leitor (RVI). ..........................................40 


\section{Lista de Apêndices}

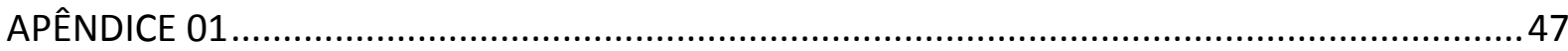

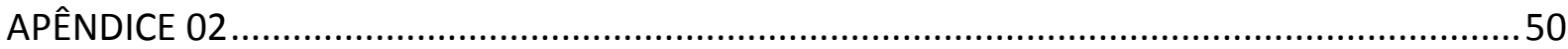

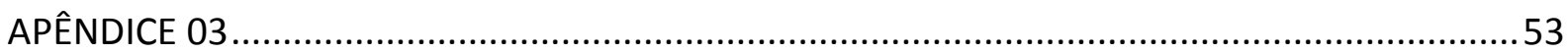

APÊNDICE 04

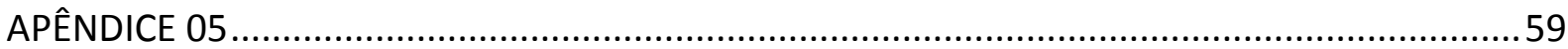

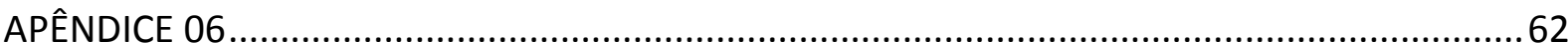

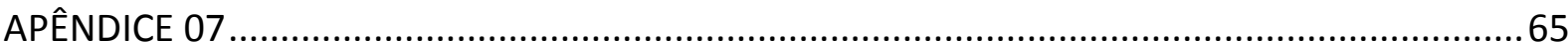

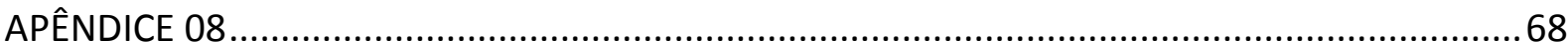




\section{Sumário}

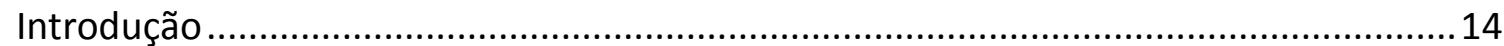

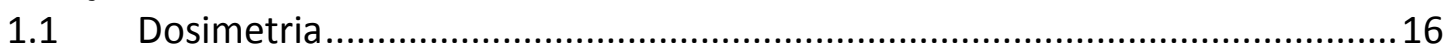

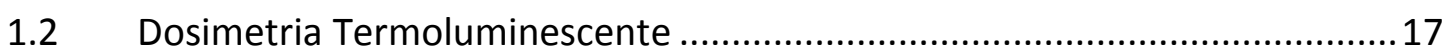

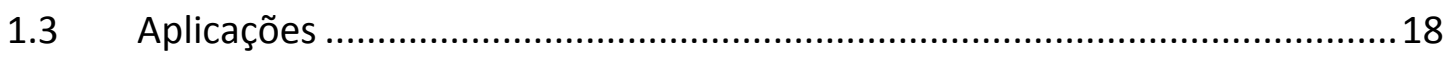

1.4 Modelo de bandas em Dosimetria TL...........................................................20

1.5 Modelo matemático para as curvas de emissão TL.......................................22

1.6 Análise da curva de emissão TL ...............................................................2 24

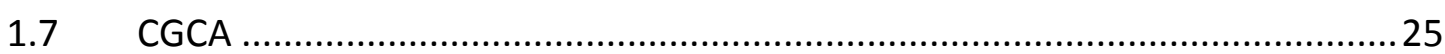

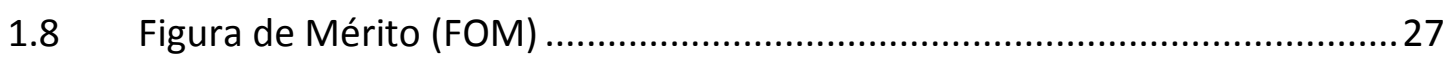

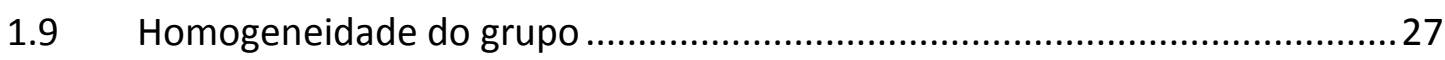

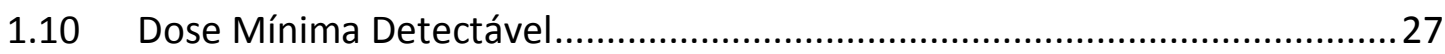

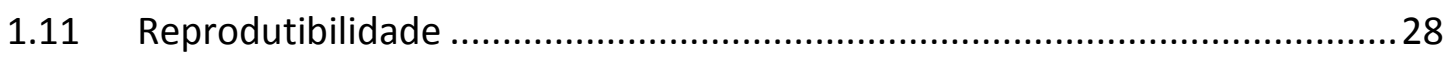

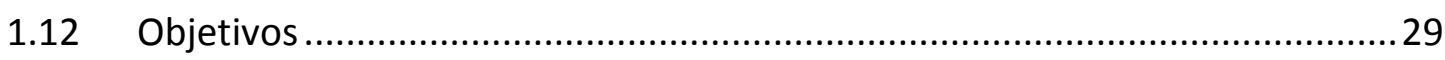

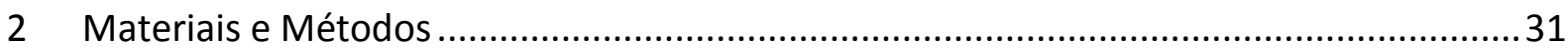

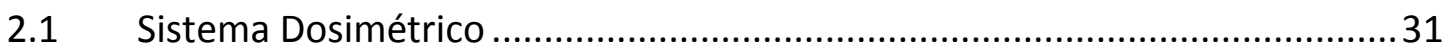

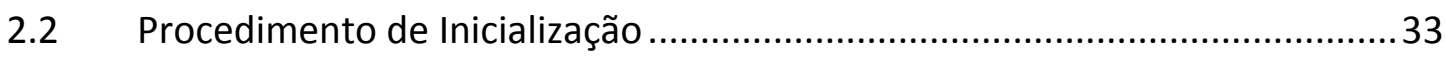

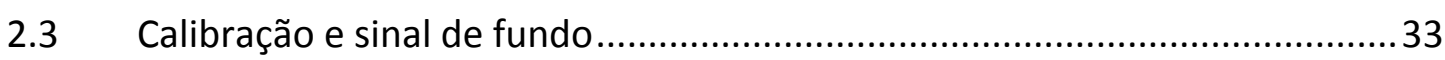

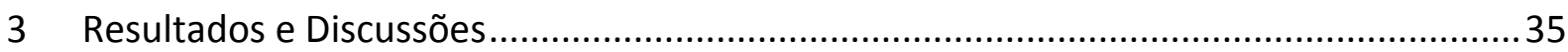

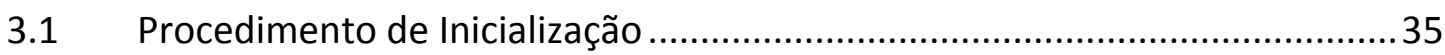

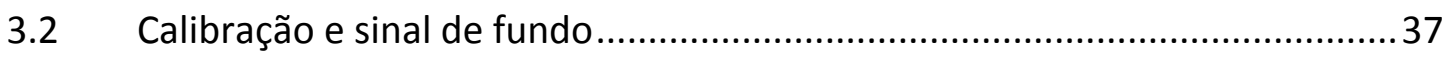

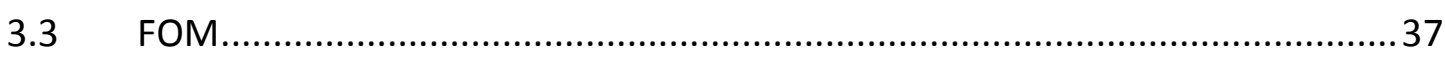

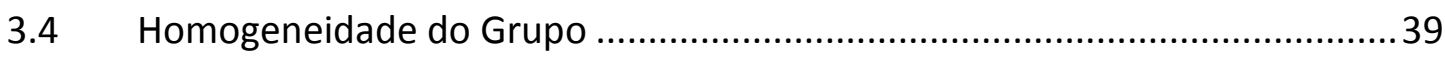

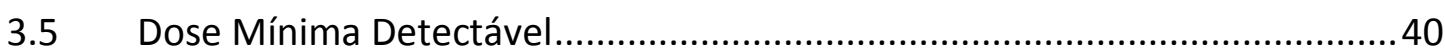

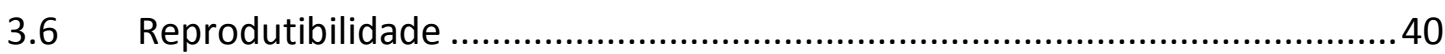

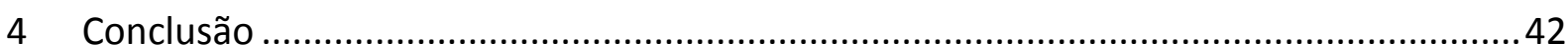

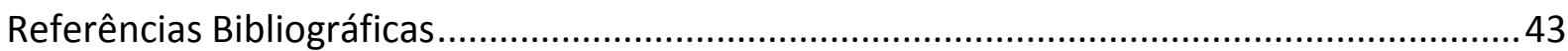




\section{Introdução}

Efeitos induzidos pela radiação em sistemas biológicos e de estado sólido, especialmente os efeitos de densidade de ionização, continuam a ter implicações de longo alcance e investigação intensiva. Sistemas de estado sólido são consideravelmente menos complexos que sistemas radiobiológicos e a modelagem física e matemática da radiação induzida nos efeitos desses sistemas atingiram um estágio mais maduro, com sucessos significativos[1].

Um bom exemplo é o centro de captura, centro luminescente e centro competitivo, sistema que dá origem a picos termoluminescentes (TL) de LiF: $\mathrm{Mg}, \mathrm{Ti}$, e os efeitos da densidade de ionização neste sistema. Embora mais simples que os mecanismos biológicos, o TL também é um processo de estágios múltiplos em que a interação entre mecanismos de recombinação localizada e delocalizada pode dar origem a muitos fenômenos complexos[1].

Nas décadas de 1960 e 1970, as primeiras investigações desse material, especificamente, os picos dosimétricos, rapidamente revelaram um número surpreendente de fenômenos que poderiam estar diretamente relacionados à densidade de ionização.

Um pouco mais tarde, nos anos 80 e no início dos anos 90, a radiação aparentemente desconectada induziu fenômenos que foram descobertos em outros sistemas baseados em LiF. Descobriu-se que ao dopar o LiF com magnésio e titânio (Mg, $\mathrm{Ti}$ ), material obtido por uma irradiação de $\sim 1000 \mathrm{~Gy}$ de sensibilização seguido por um aquecimento de $280{ }^{\circ} \mathrm{C}$ ) a supralinearidade (ou seja, maior eficiência de $\mathrm{TL}$ ) desaparece e a resposta excessiva em fótons de baixas energias também desaparece. A extensão da supralinearidade diminui com a diminuição da energia dos fótons e é dependente de um grande número de parâmetros experimentais e de campo de radiação[2].

Este resultado experimental estabeleceu claramente a conexão entre a distribuição microscópica na dose de uma única faixa (a resposta energética do fóton) e a resposta macroscópica à dose por faixas sobrepostas (a resposta à dose). Em material dopado, as LCs são preenchidas e os efeitos da densidade de ionização desaparecem. 
Um grande número de ideias foram desenvolvidas para caracterizar e explicar esses fenômenos, a resposta de dose linear / supralinear e a resposta TL relativa à partículas pesadas carregadas tiveram atenção especial[1].

A modelagem de estado sólido, foi baseada nos modelos de nível de energia da banda de condução e de valência e da teoria cinética do transporte de portadores de carga nestas bandas. As ideias eram bastante simples; supralinearidade surge da diminuição da eficiência dos processos competitivos em certos níveis de dose - comportamento que pode surgir por várias razões[1].

Por exemplo: (i) os concorrentes entram em saturação (população total) antes dos centros luminescentes[3] ou, alternadamente, (ii) o enchimento dos LCs (ou alternativamente os TCs) na irradiação / absorção estágio exibe uma resposta dose supralinista[4].

No entanto, os modelos de estado sólido são totalmente cegos aos efeitos da densidade de ionização. Assim, a modelagem de estado sólido foi, em princípio, incapaz de explicar a dependência da supralinearidade na energia dos fótons ou, a dependência de eficiências relativas de TL no tipo de radiação (densidade de ionização). Para o seu crédito, no entanto, merece menção que mesmo os modelos cinéticos muito simples são muito em predizer a forma dos picos de brilho de TL seguindo a baixa irradiação de ionização[5].

A última década, no entanto, testemunhou o surgimento de vários modelos, encabeçando através de uma compreensão mais profunda dos mecanismos de TL subjacentes, bem como na modelagem micro dosimétrica e especificamente desenvolvida para explicar a fenômenos de densidade de ionização.

Uma das desvantagens do LiF: $\mathrm{Mg}$, $\mathrm{Ti}$ é a sua sensibilidade relativamente baixa. Medições confiáveis são limitadas a níveis de dose acima de um limiar de cerca de $10^{-2}$ rad (100 $\mu \mathrm{Gy}$ ). Esta sensibilidade é adequada para muitas aplicações em dosimetria pessoal e ambiental, e de fato o TLD-100 substituiu os filmes fotográficos mais antigos na maioria das situações[6]. No entanto, uma crescente demanda por materiais equivalentes a tecidos com maior sensibilidade levou ao desenvolvimento de novas alternativas.

Uma desvantagem do uso complicado de LiF: Mg, Ti em muitas aplicações clínicas é o aumento em sua eficiência TL acima de 1 Gy[1], levando a uma resposta não-linear referida 
como supralinearidade, como já foi mencionado anteriormente. Muitas aplicações em radioterapia fornecem níveis de dose de radiação superiores a $1 \mathrm{~Gy}$, e níveis muito altos de precisão são necessárias para promover o tratamento ideal. Isto exige uma atenção muito cuidadosa aos protocolos de medição altamente detalhados, bem como à calibração demorada de todos os TLDs para corrigir essa não-linearidade da resposta à dose.

Essas propriedades podem variar de lote para lote e também podem ser uma função da exposição à radiação, reaquecimento e histórico de manuseio. Deste modo, mesmo com excelentes avanços nos estudos do TLD com relação aos tratamentos térmicos e às formas de análise da curva de emissão TL[7], é necessário continuar os estudos a fim de possibilitar a utilização desta técnica na clínica.

Nos próximos tópicos será desenvolvida a fundamentação teórica sobre a qual se sustenta este trabalho. Primeiramente será apresentado os conceitos de dosimetria e dosimetria termoluminescente, seguido das aplicações dos mesmos. Será descrito então o modelo de bandas e o modelo matemático para as curvas de emissão TL. Posteriormente será descrito os métodos de análise da curva de emissão e principalmente, o CGCA, seguido de todos os parâmetros utilizados para avaliar o método proposto e as medições realizadas. Por fim é apontado os objetivos do trabalho.

Nos próximos capítulos serão apresentados os materiais e métodos utilizados, seguido das discussões dos resultados obtidos.

\section{$1.1 \quad$ Dosimetria}

Dosimetria é a determinação de dose quando a radiação ionizante interage com a matéria. Essa quantificação ocorre por meio de um dispositivo denominado dosímetro, o qual é capaz de realizar a detecção da energia depositada em uma massa e de mensurar a dose absorvida pelo mesmo[8].

A utilização dessa técnica é de fundamental importância para proteção radiológica e para a garantia de qualidade do feixe. A dosimetria é amplamente utilizada em serviços de radioterapia e radiodiagnóstico, nos quais é imprescindível que a dose prescrita ao paciente 
seja realmente aquela fornecida pelo equipamento. Dessa forma, a sua exatidão está diretamente relacionada à dosimetria de rotina e à calibração do feixe de radiação.[9]

\subsection{Dosimetria Termoluminescente}

A dosimetria termoluminescente (TL) é a determinação da dose de radiação absorvida por meio de materiais que possuem a capacidade de emitir luz quando aquecidos. Os materiais utilizados são denominados termoluminescentes e seu funcionamento é explicado a partir do modelo de bandas para níveis de energia, mostrado na figura 01. Além disso, são, em geral, cristais isolantes, ou seja, sua camada de valência (banda de valência - BV) encontrase repleta de elétrons, enquanto a camada de condução (banda de condução - BC) encontrase vazia[10].

Para ocorrer a termoluminescência, segundo a definição termodinâmica, é necessário que o sistema, ou o material, absorva energia externa para que o elétron saia do estado de equilíbrio e seja capturado em outro metaestável de energia. Este estado está localizado em um intervalo chamado banda proibida ou gap de energia, entre a BC e a BV, da ordem de alguns elétron-volts $(\mathrm{eV})$ para materiais termoluminescentes típicos. Dessa forma, uma vez neste estado, o elétron consegue voltar à condição de equilíbrio somente quando ocorre uma relaxação termicamente estimulada[11].

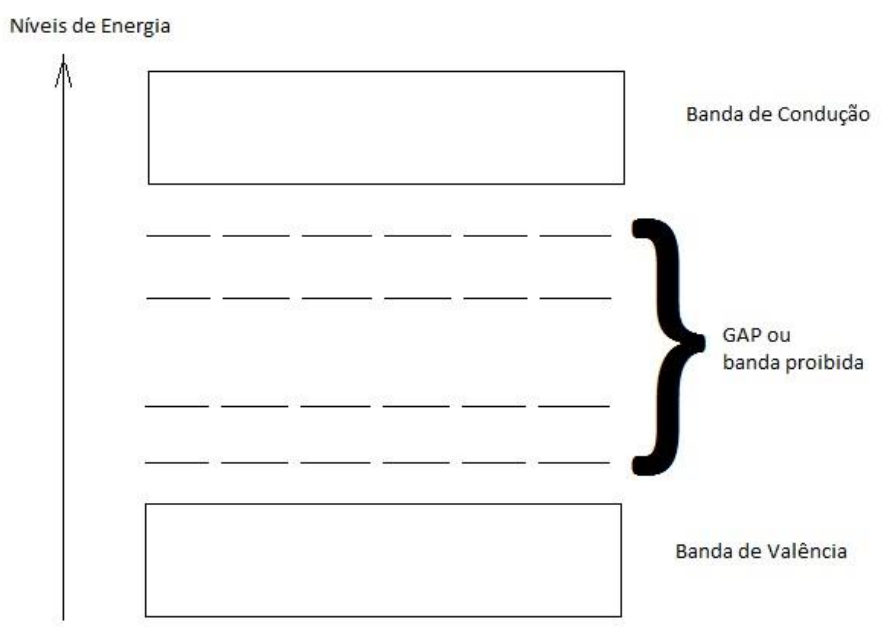

Figura 01 - Modelo de Bandas para níveis de energia. 
No caso da dosimetria TL, a radiação ionizante absorvida pelo cristal faz com que os elétrons sejam capturados nos estados metaestáveis de energia e, ao serem aquecidos, emitam radiação, geralmente, na região do visível. É esta luz emitida que será medida e correlacionada com a dose de radiação recebida pelo material.[12]

O material TL mais utilizado em radiodiagnóstico e radioterapia é o fluoreto de lítio dopado com magnésio e titânio (LiF:Mg,Ti).[13], [14] Este material pode ser produzido de diversas formas, tais como pó, bastões ou discos com dimensões pequenas (da ordem de alguns milímetros). As impurezas adicionadas ao material por meio dos elementos dopantes são determinantes para a criação dos estados metaestáveis de energia, o que torna possível a técnica dosimétrica.

O sulfato de cálcio dopado com disprósio $\left(\mathrm{CaSO}_{4}\right.$ :Dy) e o fluoreto de cálcio dopado com disprósio ( $\mathrm{CaF}_{2}$ :Dy) são mais sensíveis que o LiF:Mg,Ti e podem ser utilizados para medição de doses muito baixas. O fluoreto de lítio dopado com magnésio, cobre e fósforo (LiF:Mg,Cu,P) é até trinta vezes mais sensível que o LiF:Mg,Ti, mas sua desvantagem é a alta sensibilidade a tratamentos térmicos incorretos[13].

\subsection{Aplicações}

O radiodiagnóstico (ou radiologia diagnóstica) consiste na obtenção de informações anatômicas e funcionais do corpo humano de modo menos invasivo, utilizando a radiação ionizante. Técnicas como radiografia, tomografia computadorizada, ressonância magnética, angiografia, entre outras, fazem uso desta radiação para obtenção de um diagnóstico e, portanto, são classificadas como radiodiagnóstico[15].

Radioterapia é o nome dado ao tratamento de neoplasias locais realizado por meio de radiação ionizante, a fim de destruir células tumorais. Quando a fonte de radiação está longe do paciente, o tratamento é chamado teleterapia e é feito, principalmente, por meio de aceleradores lineares. Já a braquiterapia é o procedimento no qual o material radioativo é inserido no paciente, por meio de cateteres ou sondas controladas por um software de computador e entra em contato com as células cancerígenas[13]. 
A introdução da dosimetria TL em radiodiagnóstico e radioterapia tem uma longa história e sua utilização tem sido bem documentada na literatura[16] devido a características específicas do dosímetro de LiF, como seu tamanho, boa equivalência com tecido humano, baixa atenuação, alta sensibilidade, boa estabilidade em condições ambientais de temperatura e umidade padrão, além da alta exatidão.

Dosímetros pequenos podem ser colocados diretamente na pele, sem atrapalhar o procedimento radiológico com pouca interferência na mobilidade e conforto do paciente. Ao se escolher TLD de materiais quase equivalentes ao tecido, podem ser minimizadas as correções devido às dependências energética e angular dos dosímetros para determinação do kerma (taxa de energia cinética depositada no meio por unidade de massa) no ar, o que resulta em um processo de medição simples, com acurácia satisfatória.

Em radiodiagnóstico pesar do controle da exposição do paciente à radiação não ser tão rígido quanto na radioterapia, a utilização do TLD tem diversas funções, tais como: assegurar a dose depositada no paciente, por meio do controle de qualidade do equipamento; comparar a dose nos diferentes equipamentos de diagnóstico por imagem; e estimar o risco do paciente submetido ao exame médico[17]. Assim, a disponibilidade dos TLDs em uma grande variedade de formas físicas, os torna particularmente adequados para medições da grandeza kerma no $\operatorname{ar}[13]$.

Na radioterapia, o TLD é utilizado no controle de dose recebida pelo paciente, durante os tratamentos de braquiterapia e teleterapia, e pelas pessoas que trabalham, rotineiramente, com radiações, a fim de se assegurar os padrões estabelecidos, para o ambiente de tratamento[18].

Outras utilizações do TLD são na dosimetria ambiental através do monitoramento da dose de radiação criada a partir das operações de usinas nucleares, ou outros tipos de fontes nucleares, e o impacto dessa dose para o meio ambiente; na dosimetria de altas doses no monitoramento dentro de reatores nucleares; e na dosimetria em datação durante a determinação da idade de um material, conhecendo-se o tempo de meia vida de elementos instáveis encontrados na natureza, na qual ocorre a desintegração radioativa. 


\subsection{Modelo de bandas em Dosimetria TL}

Quando um dosímetro é exposto à radiação ionizante, os elétrons excitados migram da BV para a BC, formando pares de elétrons e buracos. Estes elétrons permanecem se deslocando, por um curto período de tempo, na banda de condução, até serem capturados pelos estados metaestáveis de energia (também chamados de armadilhas), localizados na banda proibida.

Uma vez armadilhados, os elétrons podem manter-se nesses estados de energia por um tempo que pode durar até meses, fornecendo ao dosímetro TL a vantagem de armazenamento de informações, que pode ser coletada ao se aquecer o cristal. A temperatura do aquecimento do dosímetro varia conforme o material termoluminescente[19].

A energia, sob forma de calor, absorvida pelos elétrons, faz com que estes escapem das armadilhas e retornem à banda de condução. Desta forma, os elétrons podem ser armadilhados novamente, ou podem se combinar radiativamente em centros de luminescência ativados por buracos, ou seja, o elétron se combina com o buraco no centro luminescência emitindo luz. Também podem se combinar radiativamente com buracos localizados na BV [14]. Os processos de recombinação estão representados na figura 02, e podem ser, analogamente, discutidos para os buracos com o elétron sendo o centro emissor. 
A quantidade de dose absorvida no cristal determina o número de elétrons armadilhados $\mathrm{A}$ uma dada temperatura, e, consequentemente, a quantidade de luz emitida devido à combinação radiativa desses elétrons. As armadilhas encontram-se a diversas profundidades em relação à banda de condução, na maioria dos materiais $T L$, e serão desocupadas a diferentes temperaturas, correspondentes aos diferentes estados de energias no cristal [8].

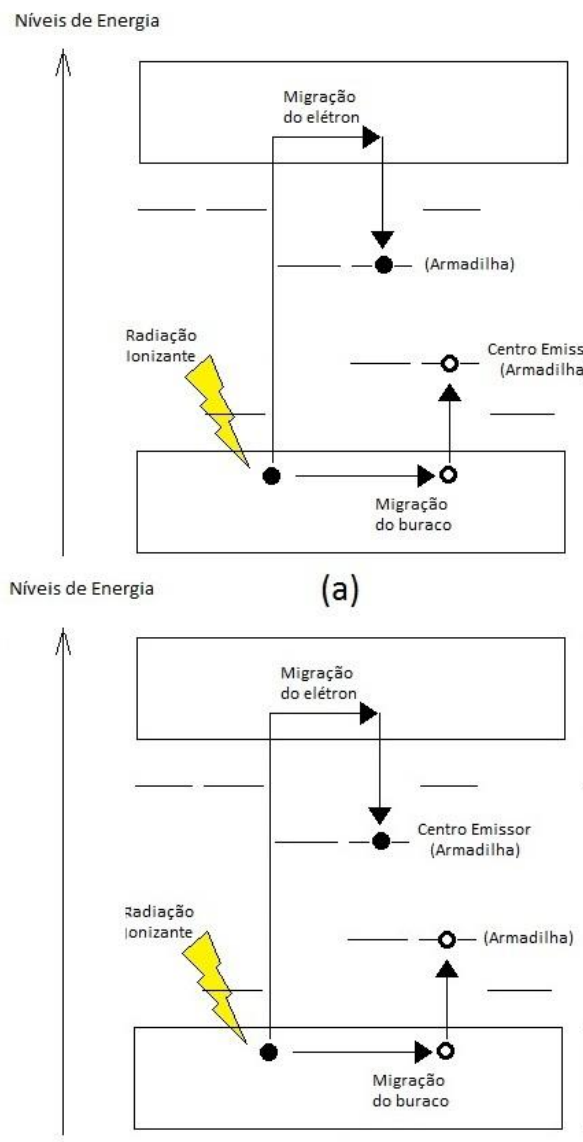

(c)

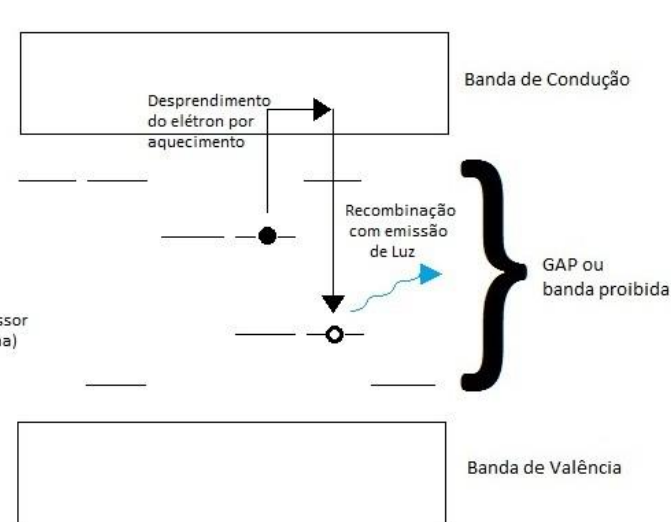

(b)

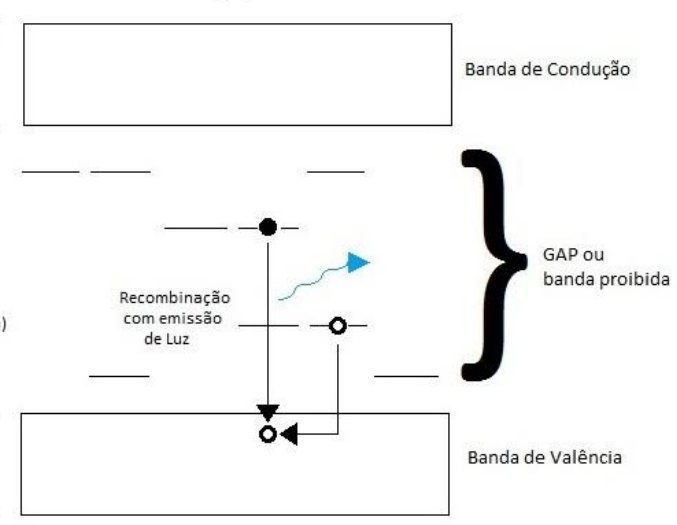

(d)

Figura 02 - Diagrama de nível de energia de um material TL. (a) Criação de par elétronburaco e buraco como centro emissor, devido exposição à radiação ionizante; (b) emissão de radiação devido à combinação radiativa no centro emissor; (c) criação de par elétron-buraco e elétron como centro emissor; (d) emissão de radiação devido à combinação radiativa com buracos na BV [20].

Desta forma, os estados de energia são representados através de picos termoluminescentes na chamada Curva de Emissão TL, que é a função que descreve a 
intensidade da luz em função da temperatura e depende do número de armadilhas no cristal. Os picos podem ser classificados como estáveis ou instáveis, ou seja, podem decair mais ou menos rapidamente com o tempo de acordo com o material, e estão presentes em todo dosímetro TL. Em dosimetria, são utilizados os picos estáveis, também conhecidos como picos dosimétricos [21].

A detecção da luz emitida pelo material é realizada por um sistema de leitura chamada leitora TL. Após a leitura, o cristal pode ou não se encontrar no seu estado original de energia, podendo haver a necessidade de um tratamento térmico especial para reutilização do mesmo [21].

\subsection{Modelo matemático para as curvas de emissão $T L$}

Primeiramente, para descrever as curvas de emissão TL matematicamente, tem-se que presumir que todas as armadilhas possam ser preenchidas com números diferentes de elétrons.

A probabilidade $p$ de um elétron deixar uma armadilha por unidade de tempo, indo para a banda de condução, é dada por:

$$
p=s \exp \left(-\frac{E}{k T}\right)
$$

em que $s$ é o fator de frequência $\left(\mathrm{s}^{-1}\right)$, que é uma constante específica da armadilha, relacionada com as vibrações da rede cristalina, $E$ é a profundidade da armadilha (eV), $k$ é a constante de Boltzmann (eVK-1) e $T$ é a temperatura absoluta (K).

Utilizando o conceito de cinética de primeira ordem, que se presume que nenhum elétron que deixe a armadilha seja rearmadilhado, então o número de elétrons armadilhados no material $n$ decresce com o tempo $t$ se a temperatura $T$ é mantida constante, como mostra a expressão:

$$
\frac{d n}{d t}=-p n
$$

Usando a equação (1) e integrando a equação (2),

$$
\int_{\mathrm{n}_{0}}^{\mathrm{n}} \frac{\mathrm{dn}}{\mathrm{n}}=-\int_{0}^{\mathrm{t}} \mathrm{s} \exp \left(-\frac{\mathrm{E}}{\mathrm{kT}}\right) \mathrm{dt}
$$


Obtém-se

$$
n=n_{0} \exp \left[-s t \exp \left(-\frac{E}{k T}\right)\right]
$$

Em que $n_{0}$ é o número de elétrons armadilhados no instante $t=0$.

Em 1945, foi utilizada uma abordagem matemática em que, para cada pico TL em uma curva de emissão, foi suposto que o cristal seja exposto a uma taxa de aquecimento $\beta=d T / d t$ constante. $\mathrm{O}$ trabalho realizado por Randall e Wilkins[22] presumiu uma cinética de primeira ordem e, consequentemente, que a intensidade da luz TL, $I$, a qualquer temperatura, é diretamente proporcional à taxa de desarmadilhamento:

$$
I(t)=-c \frac{d n}{d t}=c p n
$$

em que $c$ é uma constante

Substituindo as equações (1) e (4) na equação (5) obtemos:

$$
I(t)=n_{0} s \exp \left(-\frac{E}{k T}\right) \exp \left[-s t \exp \left(-\frac{E}{k T}\right)\right] .
$$

Utilizando $d t=d T / 6$, a partir da equação (3) tem-se:

$$
\int_{n_{0}}^{n} \frac{d n}{n}=-\frac{s}{\beta} \int_{T_{0}}^{T} \exp \left(-\frac{E}{k T^{\prime}}\right) d T^{\prime}
$$

$E$, de novo

$$
n=n_{0} \exp \left[-\frac{s}{\beta} \int_{T_{0}}^{T} \exp \left(-\frac{E}{k T^{\prime}}\right) d T^{\prime}\right]
$$

Substituindo a equação (8) na (5)

$$
I(T)=n_{0} s \exp \left(-\frac{E}{k T}\right) \exp \left[-\frac{s}{\beta} \int_{T_{0}}^{T} \exp \left(-\frac{E}{k T^{\prime}}\right) d T^{\prime}\right]
$$

Esta expressão pode ser avaliada por integração numérica e produz uma curva em forma de sino, com um máximo de intensidade a uma temperatura característica $T_{m}$.

Uma expressão simplificada da equação (9) pode ser utilizada para descrever a intensidade da luz emitida em função da temperatura na análise da curva de emissão TL [23]:

$$
I(T)=I_{m} \exp \left[1+\frac{E}{k T} \frac{T-T_{m}}{k T}-\frac{T^{2}}{T_{m}^{2}} \times \exp \left(\frac{E}{k T} \frac{T-T_{m}}{k T}\right)(1-\Delta)-\Delta_{m}\right]
$$


em que $I_{m}$ é o máximo de intensidade da luz TL na temperatura $T_{m}$, em K, $E$ é a energia de ativação, em eV, $k$ é a constante de Boltzmann, em eV $(\mathrm{K})^{-1}, \Delta$ é $2 k T / E$ e $\Delta_{m}$ é $2 k T_{m} / E$.

Ao utilizar a forma reduzida da equação (9), a informação sobre os parâmetros de armadilhamento, $s$ e $n_{0}$, é perdida, o que na maior parte das aplicações dosimétricas não é relevante. A equação (10) pode ser usada para análise matemática da curva de emissão e as formas de avaliação serão discutidas na próxima seção.

A figura 03 mostra uma curva de emissão TL típica de um dosímetro utilizando a cinética de primeira ordem.

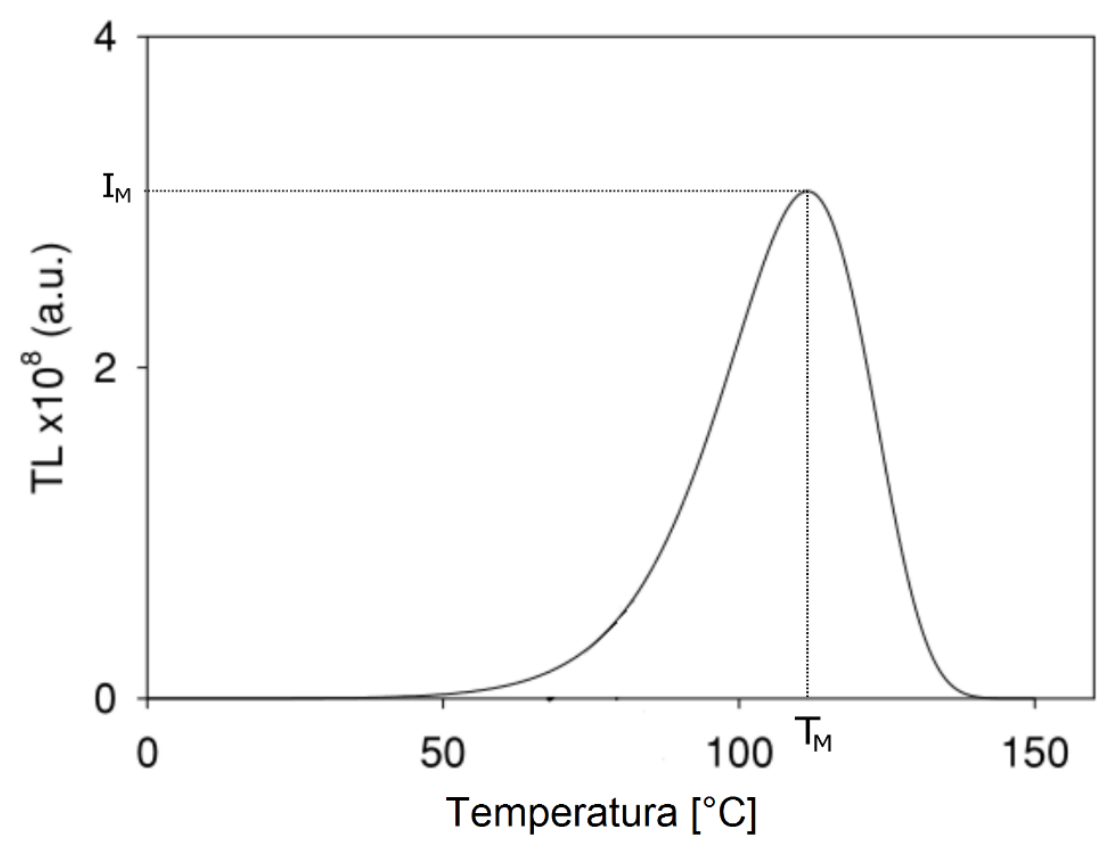

Figura 03 - Curva de emissão TL típica de um dosímetro utilizando a cinética de primeira ordem[24].

\subsection{Análise da curva de emissão $T L$}

Há diversas formas de avaliar o sinal TL. O primeiro método é medir a altura do pico no pico dosimétrico. Este método tem algumas possíveis desvantagens. Em doses baixas, a altura do pico pode sofrer flutuações estatísticas muito maiores do que para um sinal TL integrado, e no caso de curvas de emissão complexas, a altura de pico pode ser influenciada por picos vizinhos/sobrepostos, cujas características dosimétricas sejam diferentes. 
Um segundo método baseia-se na integração do sinal de TL entre duas temperaturas prédeterminadas que definem a chamada "região de interesse", ROI, do inglês Region Of Interest. Mais do que uma ROI podem ser aplicadas simultaneamente. Este método atenua a flutuação estatística sofrida por métodos de altura de pico, mas continua baseada na sobreposição dos vários picos e na escolha subjetiva da temperatura do vale, que pode se deslocar por causa de flutuações instrumentais.

Um terceiro método, chamado de CGCA simplificada, do inglês Computerized Glow Curve Analysis, analisa a forma ou perfil da curva de emissão e a/o compara com curvas de emissão registradas anteriormente.

Finalmente, o quarto método é realizar a deconvolução completa da curva de emissão. Este método tem o potencial de fornecer maior quantidade de informação, mas o tempo e esforço envolvidos não podem ser justificados em situações práticas ou quando a exatidão é um requisito importante[20].

\section{$1.7 \quad C G C A$}

Depois dos procedimentos de inicialização e calibração terem sido realizados, os dosímetros irradiados são lidos e os valores tratados computacionalmente pelo método CGCA, por meio de um algoritmo executado no software MATLAB.

O método consiste na deconvolução da curva de emissão resultante da leitura de cada dosímetro, a fim de transformar esta curva em vários picos de emissão, utilizando a cinética de primeira ordem [12].

O programa ajusta os dados da curva de emissão TL em uma somatória de funções similares à equação (10) com diferentes valores de energia, temperatura e intensidade para cada pico. Os tipos de TLD para qual o programa foi construído são o LiF:Mg,Ti, CaF2:Dy, $\mathrm{CaF}_{2}: \mathrm{Tm}, \mathrm{CaF}_{2}: \mathrm{Mn}$, LiF:Mg,Cu,P e o $\mathrm{CaSO}_{4}: \mathrm{Dy}$ (TLD-100, TLD-200, TLD-300, TLD-400, TLD-700H e TLD-900, respectivamente), em que o número de picos e os parâmetros do ajuste varia de acordo com o TLD operado [24]. 
A figura 04 mostra a curva de emissão $(I X T)$ do LiF:Mg,Ti TLD-100. Este possui cinco picos principais, no qual os picos 4 e 5 são estáveis, ou seja, são picos dosimétricos[7].

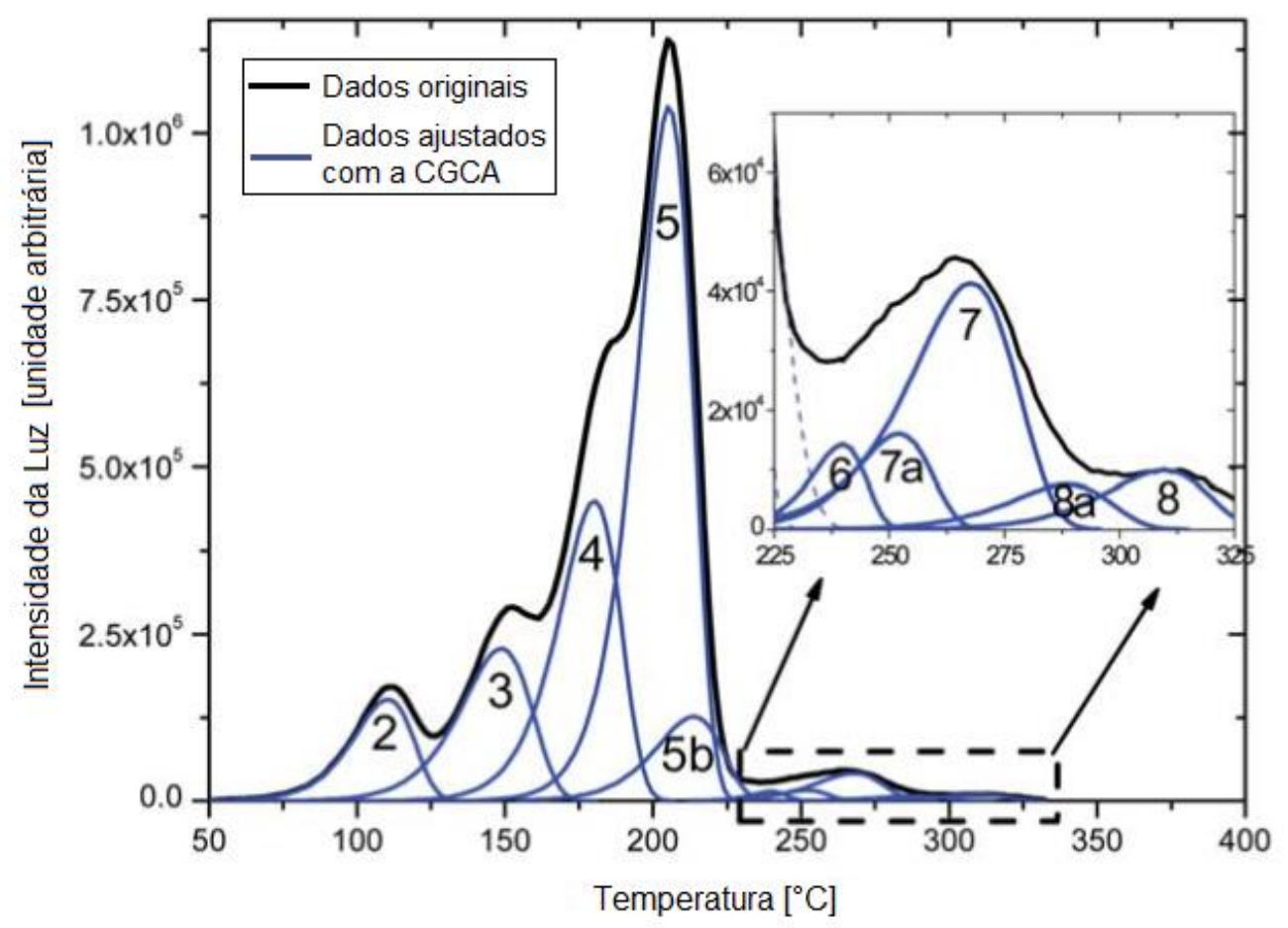

Figura 04 - Curva de emissão típica do LiF:Mg,Ti mostrando a curva original e os picos dissociados após a deconvolução[7].

Os dados coletados e os parâmetros calculados geram um gráfico de intensidade por temperatura $(I \times T)$ comparando a curva original e os picos dissociados. Novos parâmetros são gerados e armazenados em um novo arquivo, para análise de desempenho do grupo de dosímetros.

Os parâmetros arquivados são denominados $s e q_{\text {num }}$, tal, chip $_{\text {num }}$, date, time que se referem à ordem de leitura do dosímetro, data da leitura no formato ano, mês e dia (YYYYMMDD) e horário da leitura no formato horas, minutos e segundos (HHMMSS).

Também são calculados o $F O M,\{E\},\{I\},\{T\}$ e $\{A\}$ que se referem à figura de mérito (FOM), à excentricidade, intensidade, temperatura e área dos picos, respectivamente. Os valores são separados em mínimo, máximo e o valor real do ajuste. No caso do LiF:Mg,Ti também constam os valores de ajuste do sinal de fundo exponencial do dosímetro [12]. 
Este novo arquivo será utilizado para o cálculo da homogeneidade do grupo, a mínima dose detectável e a reprodutibilidade do sistema dosimétrico.

\subsection{Figura de Mérito (FOM)}

A qualidade do ajuste realizado após cada leitura utilizando o método CGCA, é medido por meio de um parâmetro chamado figura de mérito, do inglês "Figure of Merit" (FOM), representado na equação abaixo:

$$
\operatorname{FOM}(\%)=\sum_{j_{\text {start }}}^{j_{\text {stop }}} \frac{\left|y_{j}-y\left(x_{j}\right)\right|}{A} \times 100
$$

onde $j_{\text {start }}$ e $j_{\text {stop }}$ são as temperaturas inicial e final, respectivamente, na região do ajuste, $y_{j}$ é a corrente no tubo fotomultiplicador na temperatura $j, y(x j)$ é o valor da função de ajuste no canal $j$, e $A$ é a área sob o pico, i.e., a integral da função de ajuste entre $j_{\text {start }}$ e $j_{\text {stop. }}$ Os autores da equação do FOM consideram um bom ajuste, valores menores que 2,5 \% [25].

\subsection{Homogeneidade do grupo}

Logo após o procedimento de calibração, os dosímetros foram tratados, irradiados e lidos pela leitora TL, um ciclo reproduzido cinco vezes. Com base nas leituras, a homogeneidade do grupo foi determinada por meio do desvio padrão porcentual dos valores da emissão TL de cada dosímetro, sendo utilizada para comparação do desempenho dos dosímetros, a partir da análise do valor médio, da intensidade do pico principal antes e depois de realizada a deconvolução pelo método do CGCA, da área total e da área do pico principal. O teste que apresentou melhor resultado foi selecionado para a realização dos testes posteriores [24].

\subsection{Dose Mínima Detectável}

A quantidade mínima de dose detectável, também chamada de Lower Detection Limit $D_{L D L}$, é definida como sendo três vezes o valor do desvio padrão $\sigma_{B G}$ da leitura sem nenhuma 
dose irradiada, ou seja do sinal de fundo, após o tratamento térmico ter sido realizado. A dose mínima detectável é expressa em unidades de dose absorvida (Gy) [25].

$$
D_{L D L}=3 \sigma_{B G}
$$

Para obtermos o $D_{L D L}$, precisamos considerar o fator de calibração da leitora TL, $\phi_{C}$, dado por:

$$
\phi_{C}=\frac{D_{C}}{\bar{M}}=\frac{D_{C}}{1 /{ }_{N} \sum_{i=1}^{N}\left(M_{i}-M_{0 i}\right)},
$$

em que $D_{C}$ é a dose de calibração, $N$ é o número de TLDs, $M_{i}$ é a emissão TL do iésimo TLD e $M_{0 i}$ é sua emissão TL sem nenhuma dose irradiada. O erro relacionado ao fator de calibração é:

$$
\left(\frac{\Delta \phi_{C}}{\phi_{C}}\right)^{2}=\left(\frac{\Delta D}{D}\right)^{2}+\left(\frac{\Delta M}{M}\right)^{2}
$$

portanto, obtemos

$$
D_{L D L}=3 \sigma_{B G} \cdot \phi_{C}
$$

Referências literárias[26]-[28] citam valores de $D_{L D L}$ para o LiF TLD-100 de até $100 \mu \mathrm{Gy}$, No entanto, este valor é baseado em variações aleatórias no sinal de fundo inerente e não leva em conta a precisão exigida no ambiente clínico. A dose mais baixa que pode ser medida com um grau especificado de precisão pode ser consideravelmente maior do que este limite[29].

\subsection{Reprodutibilidade}

Uma maneira de representar a reprodutibilidade de um sistema dosimétrico é fazendo uma análise estatística com um grupo de dosímetros, que são tratados, irradiados e medidos várias vezes. Deste modo, podemos determinar o coeficiente de variação, dado pelo desvio padrão e pela média dos dados coletados de cada dosímetro [25].

Podemos definir coeficiente de variação (CV) como: 
$\checkmark$ SVI (Índice de Variabilidade do Sistema, do inglês System Variability Index): é o parâmetro que mede a reprodutibilidade de todo o sistema, calculado utilizando-se o valor médio do desvio padrão porcentual dos dosímetros TL.

$\checkmark$ RVI (Índice de Variabilidade do Leitor, do inglês Reader Variability Index): é o parâmetro que mede a reprodutibilidade em relação à leitora TL utilizando o desvio padrão porcentual do valor médio das medidas de cada dosímetro.

$\checkmark$ DVI (Índice de Variabilidade do Detector, do inglês Detector Variability Index): é o parâmetro que mede a reprodutibilidade em relação aos dosímetros TL e é definida pela equação

$$
D V I=\sqrt{(S V I)^{2}-(R V I)^{2}},
$$

Esse termo está relacionado à precisão da medida da TL e está sempre associado às incertezas aleatórias que são caracterizadas pelo desvio padrão[30]. De acordo com o Padrão do Comitê Eletrotécnico Internacional (IEC), a reprodutibilidade expressa como coeficiente da variação do valor-dose avaliado não deve exceder 7,5\% para cada dosímetro separadamente e $\mathrm{n}$ dosímetros coletivamente, para uma determinada dose[31].

Todas as análises mencionadas anteriormente foram realizadas no presente trabalho e são discutidas no capítulo três.

\subsection{Objetivos}

A presente proposta tem como objetivo implementar uma análise computadorizada da curva de emissão CGCA, usando um formato padrão de pacote de matemática disponível comercialmente, O MATLAB, com uma entrada que pode ser obtida a partir do software de controle, fornecido com a leitora TL, disponível no Laboratório de Física Radiológica e Dosimetria do Departamento de Física da Faculdade de Filosofia Ciências e Letras de Ribeirão Preto (FFCLRP) da Universidade de São Paulo (USP).

A implementação e o uso da CGCA na dosimetria TL clínica possibilitará melhor exatidão, ou seja, melhor garantia da qualidade, um requisito importante nas medições em radiodiagnóstico e radioterapia. 
A operação ótima de um serviço de dosimetria TL para fornecer alta exatidão na avaliação de dose requer controle cuidadoso de um grande número de parâmetros de influência. Por esta razão, uma boa qualidade é essencial para a correta utilização dos dosímetros TL. Foram estudados todos os parâmetros de influência para o funcionamento de um serviço de dosimetria $\mathrm{TL}$, em radiodiagnóstico e em radioterapia.

Foi estudado também a influência do tempo de tratamento térmico na qualidade da curva de emissão do dosímetro, testando-se um tratamento alternativo ao reduzir o tempo de aquecimento no forno de 2 horas para 15 minutos, a fim de otimizar o tempo de preparo do dosímetro. 


\section{Materiais e Métodos}

\subsection{Sistema Dosimétrico}

Um sistema dosimétrico termoluminescente é composto por vários elementos: os dosímetros termoluminescentes; uma leitora termoluminescente com um sistema de aquecimento integrado, um tubo fotomultiplicador e os circuitos eletrônicos associados. Também são necessários: um algoritmo apropriado para converter para dose o sinal TL dado pela leitora, fornos e estufas, utilizados nos tratamentos térmicos dos dosímetros TL [32]. O sistema dosimétrico simplificado está representado na figura 04.

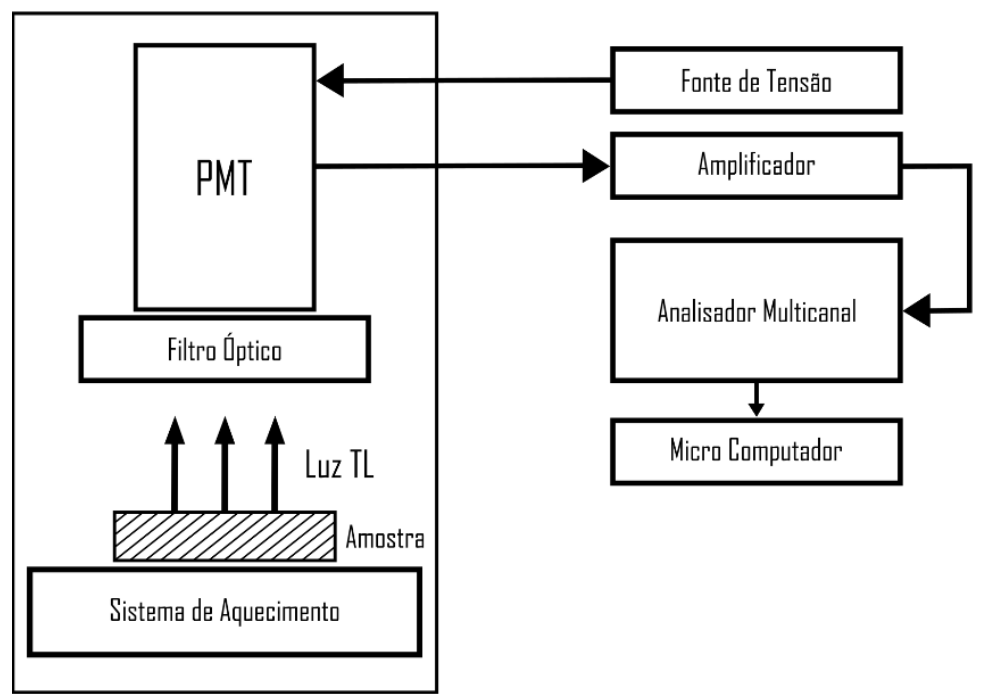

Figura 04 - Sistema dosimétrico simplificado [32].

O Laboratório de Física Radiológica e Dosimetria do Departamento de Física, FFCLRP da Universidade de São Paulo (USP), conta com centenas de dosímetros TL, de fluoreto de lítio dopado com magnésio e titânio (LiF:Mg,Ti), uma leitora TL manual, da marca Harshaw, modelo 3500, para a avaliação dos dosímetros, apresentada na figura 05 - (a), um forno e uma estufa, para serem utilizados nos tratamentos térmicos dos dosímetros, além de sistemas de irradiação. Foram utilizadas uma unidade de radiodiagnóstico convencional e uma fonte de ${ }^{137} \mathrm{CS}$, ambas pertencentes ao Centro de Instrumentação, Dosimetria e Radioproteção (CIDRA), da FFCLRP, da USP. 
Nesse trabalhou, utilizou-se 100 (cem) dosímetros TL de LiF:Mg;Ti (3,1×3,1×0,89 mm) identificados por números escritos com grafite. Utilizou-se uma pinça para manipulação dos dosímetros, indicados na figura $05-$ (b).

(a)
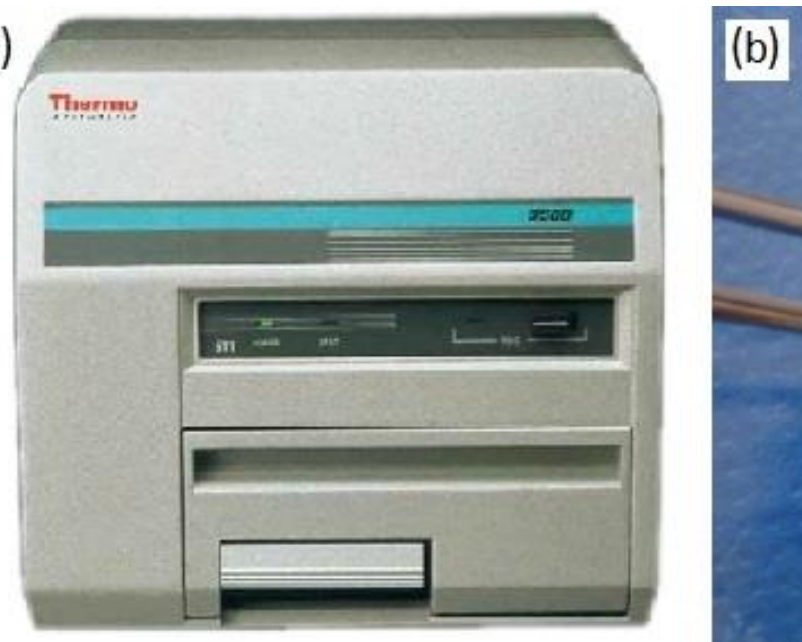

Figura 05 - (a) Leitora Harshaw, modelo 3500; (b) Dosímetros TL de LiF:Mg,Ti e pinça para manipulação dos dosímetros

As curvas de emissão serão obtidas a partir do software de controle, disponível com a leitora TL, chamado WinREMS, e a CGCA simplificada será implementada utilizando uma versão do MATLAB, também disponível no laboratório.

Princípios gerais para a utilização de dosímetros TL deverão ser seguidos [33], bem como a implementação da CGCA será baseada no trabalho de HARVEY, et al [12]. O programa ajusta os dados das curvas de emissão a uma soma de funções similares à equação 10 , com diferentes termos $E, T, T m$ e $I m$, para cada pico, utilizando um método de mínimos quadrados, para funções não lineares nos parâmetros e o algoritmo de Levenberg-Marquardt para minimização [29], [34], [35].

Medições de dose utilizando objetos simuladores serão realizadas para avaliação do desempenho da unidade de radiodiagnóstico convencional (testes de constância) [36]. A avaliação e a expressão das incertezas de medição serão feitas de acordo com as recomendações dadas no texto “Guia para a expressão da incerteza de medição"[20]. 
A utilização de dosímetros TL requer vários procedimentos antes de algum resultado ser registrado. Tais procedimentos são descritos nas seções a seguir.

\subsection{Procedimento de Inicialização}

Um procedimento de inicialização é necessário para se reduzir variações de desempenho dos TLDs. Primeiramente, um tratamento térmico nos dosímetros de LiF:Mg, Ti, é geralmente indicado pelo fabricante, na qual são necessárias de 4 a 6 horas de aquecimento[8].

Mas neste trabalho, um tratamento rápido foi utilizado para se verificar a influência do tempo no desempenho dos dosímetros, a fim de minimizar o tempo do procedimento e tornar mais viável a utilização do mesmo na clínica, sem impactar na sua sensibilidade e precisão [11].

O tratamento térmico testado consiste em um aquecimento de 15 minutos após o forno atingir a temperatura de $400^{\circ} \mathrm{C}$, com o objetivo de esvaziar as armadilhas mais profundas que os picos dosimétricos (picos 4 e 5), minimizando o sinal TL residual. Este primeiro aquecimento também tem a finalidade de restaurar o estado original da sensibilidade e da curva de emissão do dosímetro.

Após o primeiro aquecimento, o dosímetro foi resfriado até a temperatura ambiente para, depois, ser colocado na estufa para um segundo aquecimento de 10 minutos, a $100^{\circ} \mathrm{C}$. Este aquecimento tem o propósito de minimizar a contribuição de picos de baixa temperatura, através da redução do decaimento térmico do sinal TL [21].

\subsection{Calibração e sinal de fundo}

Após realizado o tratamento térmico, foi realizado um procedimento de calibração e medição do sinal de fundo dos dosímetros. Primeiramente, foi feito uma irradiação dos dosímetros TL com a fonte de ${ }^{137} \mathrm{Cs}(661,7 \mathrm{keV})$, pertencente ao CIDRA, com uma dose de 8,084 mGy $( \pm 0,001 \mathrm{mGy})$. 
Em seguida foi realizado a leitura na leitora $T L$, com uma taxa de aquecimento de $10^{\circ} \mathrm{C} / \mathrm{s}$ variando-se a temperatura de $50^{\circ} \mathrm{C}$ a $300^{\circ} \mathrm{C}$. Logo depois, os tratamentos térmicos foram realizados novamente e a leitura é feita sem que os dosímetros sejam irradiados. Este processo foi executado cinco vezes e os dados avaliados computacionalmente. 


\section{Resultados e Discussões}

\subsection{Procedimento de Inicialização}

Foi realizado um tratamento térmico rápido no grupo de cem dosímetros de LiF:Mg,Ti e sua avaliação para verificação do sinal de fundo. A eficácia do tratamento térmico está sendo mostrada no espectro de emissão representado nas figuras 06 e 07, em que se pode perceber uma leitura próxima a zero nos dez dosímetros TL escolhidos aleatoriamente. Os picos apresentados em alguns dosímetros são desprezíveis por não representarem picos termoluminescente e sim caracterizarem ruídos na leitura do sinal.

a)

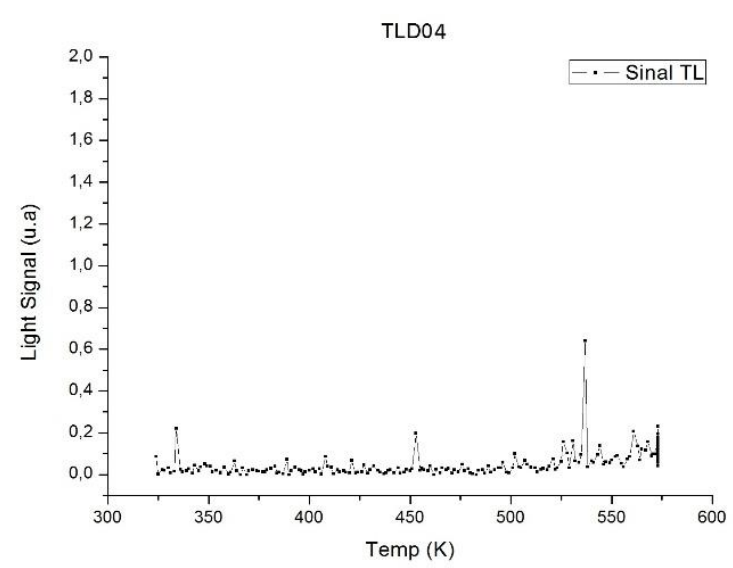

c)

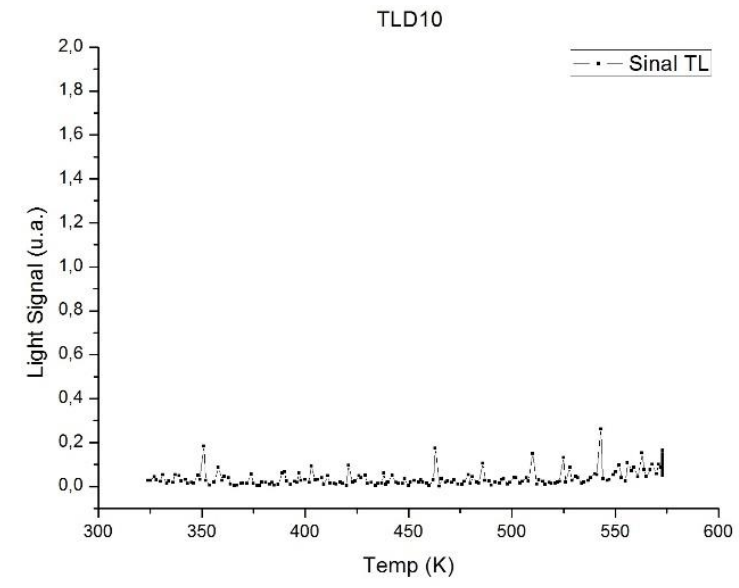

b)

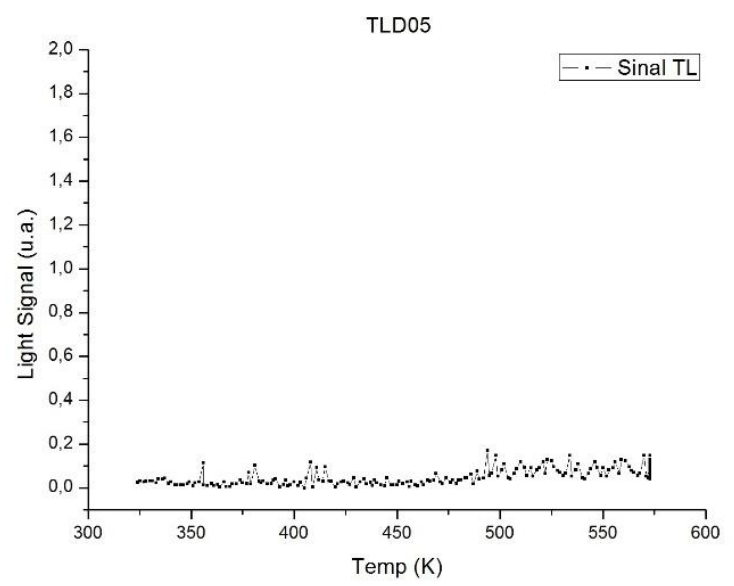

d)

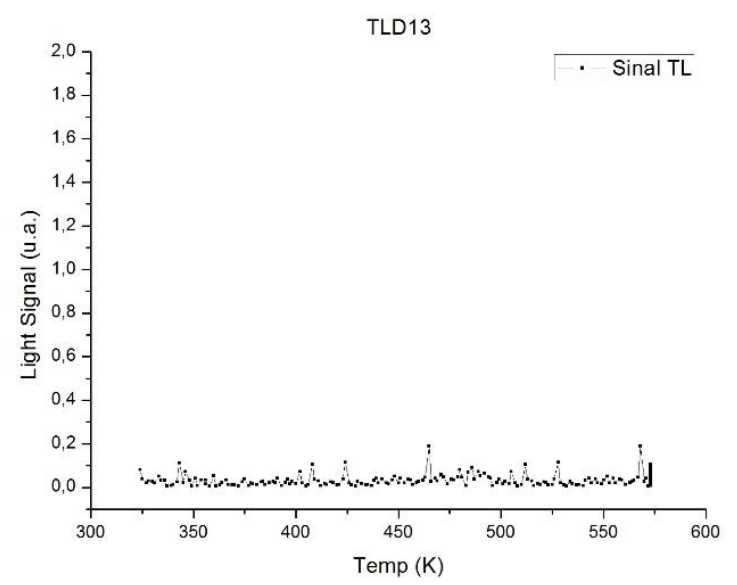

Figura 06 - Espectros de emissão TL do sinal de fundo dos dosímetros: (a) 04; (b) 05; (c)10; e (d) 13 . 
a)

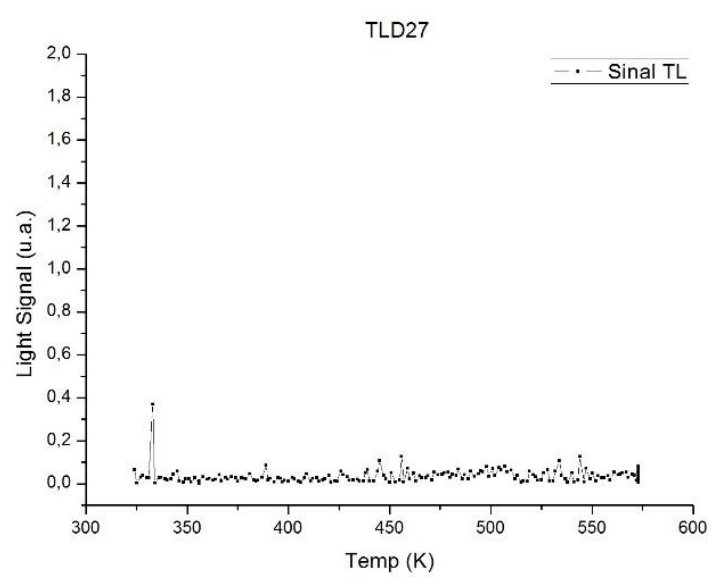

c)

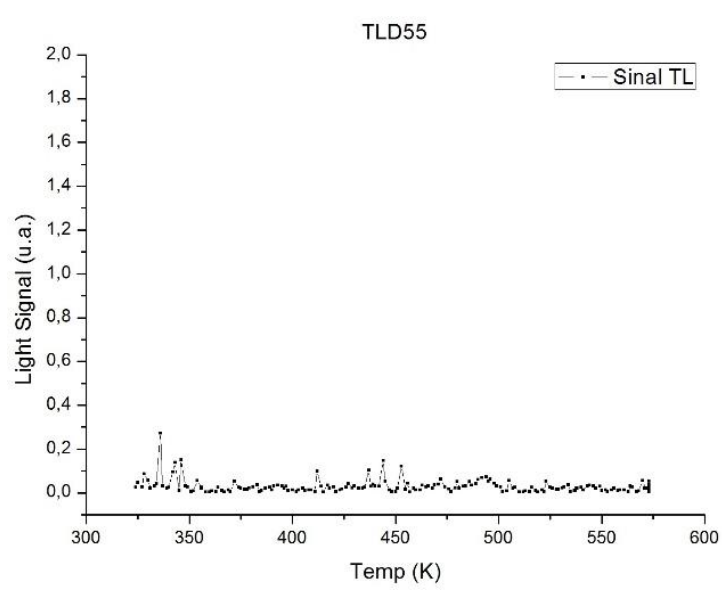

e)

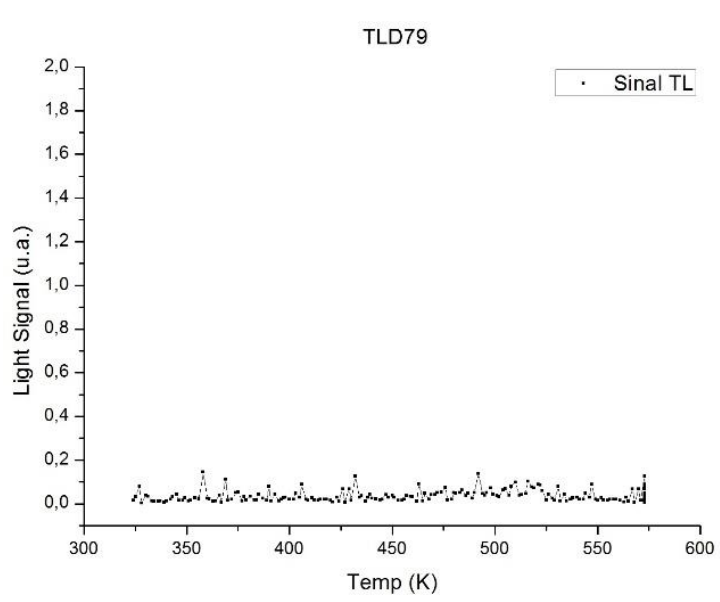

b)

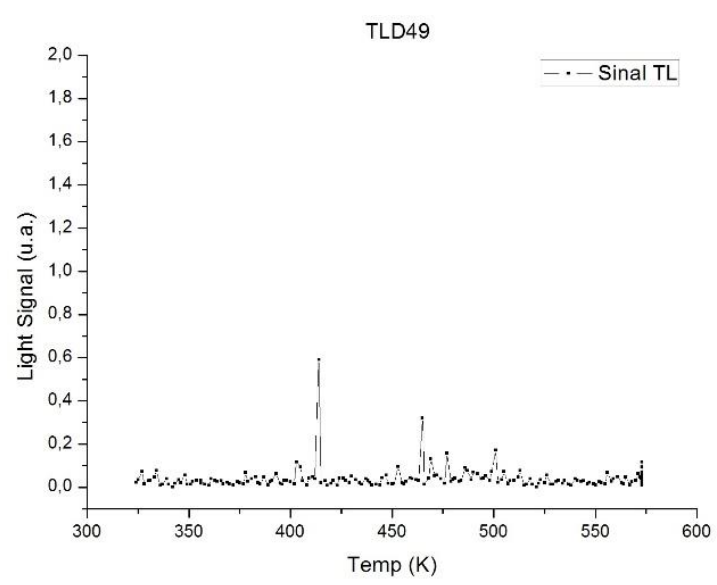

d)

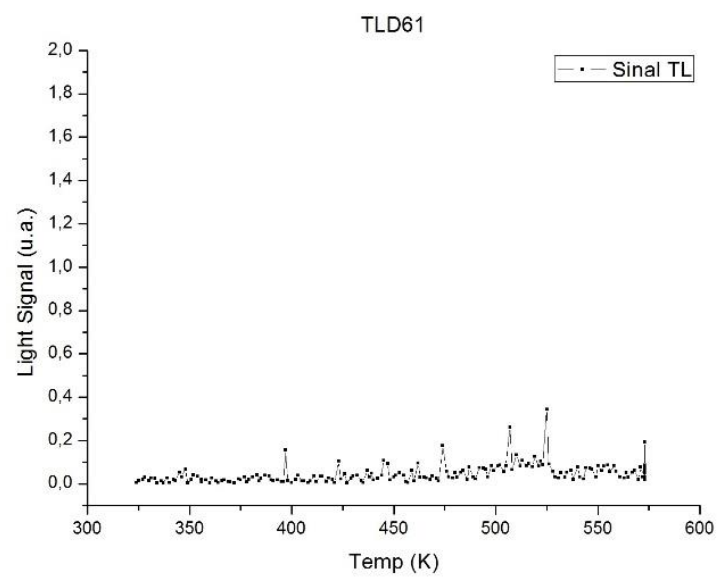

f)

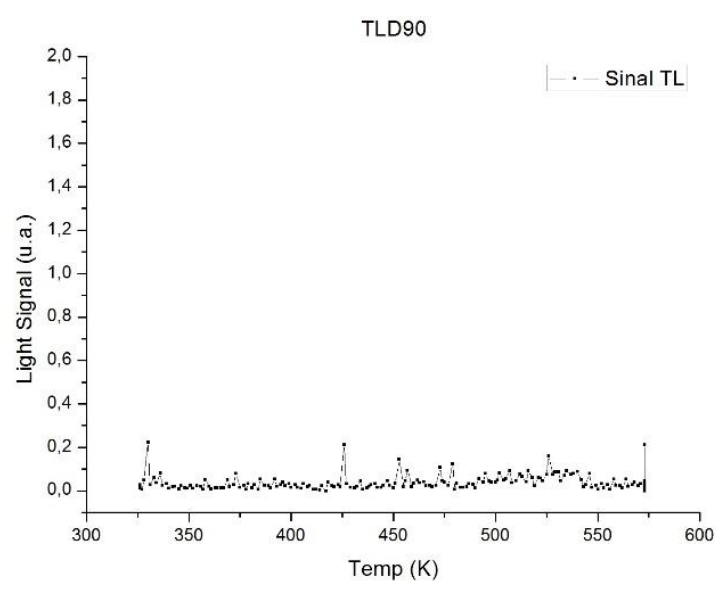

Figura 07 - Espectros de emissão TL do sinal de fundo dos dosímetros: (a)27; (b)49;

(c)55; (d)61; (e)79; e (f)90. 


\subsection{Calibração e sinal de fundo}

O procedimento de calibração foi executado cinco vezes e os resultados do sinal de fundo foram obtidos e mostrados na tabela do apêndice 01 . Os valores foram analisados de acordo com a média e o desvio padrão do sinal TL, e estão apresentados na tabela 01.

Tabela 01 - Análise do sinal de fundo por meio do valor médio $\overline{\mathrm{M}_{0}}$ e do desvio padrão $\left(\sigma_{B G}\right)$ porcentual.

\begin{tabular}{cccccccc}
\hline Ciclo & 1 & 2 & 3 & 4 & 5 & $\overline{\mathrm{M}_{0}}$ & $\sigma_{B G}(\%)$ \\
\hline$\overline{\mathrm{M}_{0}}$ & 0,245 & 0,204 & 0,279 & 0,239 & 0,201 & 0,234 & 3,20 \\
$\sigma_{B G}(\%)$ & 12,18 & 18,87 & 20,17 & 14,45 & 0,080 & &
\end{tabular}

O procedimento de inicialização é importante para otimizar os resultados obtidos de resposta do TLD para que não sofram alterações durante o seu uso, e, portanto, os valores obtidos de desvio padrão porcentual dos $M_{0}$ e $\overline{M_{0}}$, contribuem de modo a reduzir as possibilidades de mudanças de características do dosímetro. Contudo, somente a análise do sinal de fundo não é suficiente, devido ao fato de que podem restar armadilhas profundas, permanentemente não preenchidas, o que lhes confere uma resposta ainda instável.

\subsection{FOM}

O FOM foi calculado utilizando-se a equação 11 por meio da CGCA e os resultados obtidos estão mostrados nos histogramas a seguir. Os dados originais podem ser vistos na tabela do apêndice 02 .

Como os autores da equação do FOM consideram um bom ajuste valores menores que 2,5\%, então, alguns dosímetros devem ser descartados por possuírem valores maiores que o desejado [24]. A tabela 02 mostra que o dosímetro que apresentou maior FOM foi o 84, e é apresentado na figura 08, e o menor FOM foi o 95, e é apresentado na figura 09.

Tabela 02 - Análise do FOM obtido dos dosímetros.

\begin{tabular}{cccc}
\hline FOM $_{\operatorname{máx}}$ & 9,793 & $\mathrm{~N} \#$ & 84 \\
\hline FOM $_{\min }$ & 1,042 & $\mathrm{~N} \#$ & 95 \\
\hline
\end{tabular}


Resultados e Discussões

38

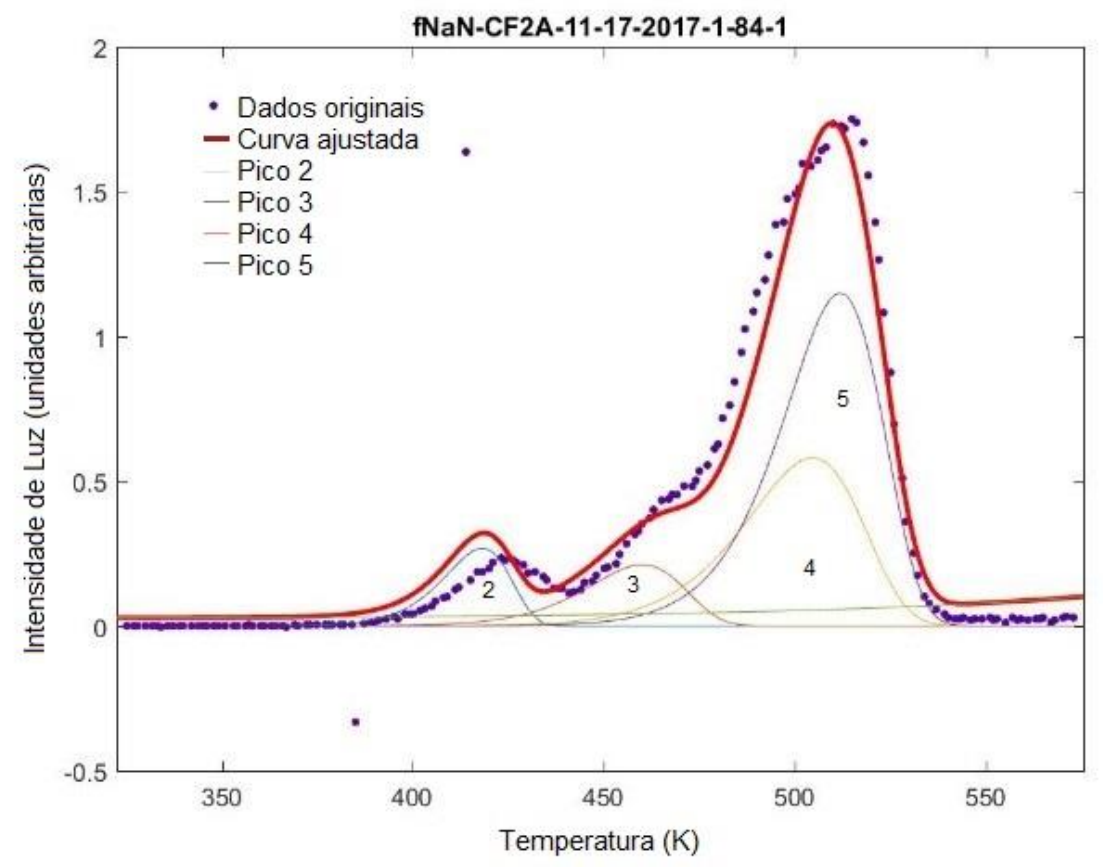

Figura 08 - Espectro de emissão TL do dosímetro 84 de LiF:Mg,Ti irradiado à 8,084 mGy com uma fonte de ${ }^{137} \mathrm{Cs}$ de energia de $661,7 \mathrm{keV}$, cujo parâmetro FOM é 9,793\% e é o maior do grupo de dosímetros.

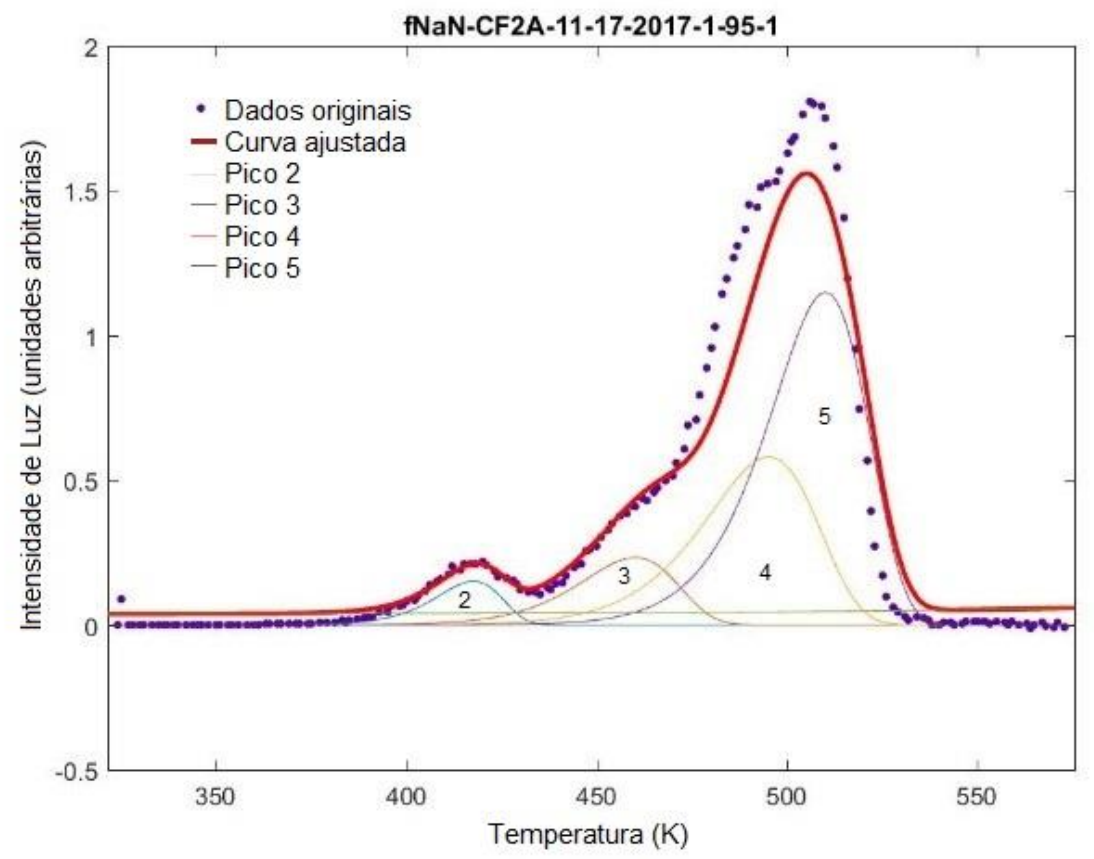

Figura 09 - Espectro de emissão TL do dosímetro 95 de LiF:Mg,Ti irradiado à 8,084 mGy com uma fonte de ${ }^{137} \mathrm{Cs}$ de energia de $661,7 \mathrm{keV}$, cujo parâmetro FOM 1,042\% e é o menor do grupo. 


\subsection{Homogeneidade do Grupo}

A homogeneidade do grupo foi calculada utilizando os valores da resposta TL, após serem irradiados com uma dose de $8,084 \mathrm{mGy}$ da fonte de ${ }^{137} \mathrm{C}$. Os testes foram realizados a fim de comparar os resultados a partir da análise do valor médio, da intensidade do pico principal antes e depois de realizada a deconvolução pelo método do CGCA, da área total e da área do pico principal, utilizando o desvio padrão e a média das leituras do grupo. Os resultados obtidos para os cinco ciclos estão apresentados nas tabelas dos apêndices 03, 04, 05, 06 e 07.

Analisando os dados das tabelas e comparando a homogeneidade por meio do desvio padrão porcentual do grupo em cada irradiação, o melhor resultado foi obtido a partir da intensidade do pico principal, ou seja, pico 5, após a deconvolução realizada pelo método CGCA, como mostra a tabela 03.

Tabela 03 - Análise do desvio padrão porcentual a partir da análise do valor médio, da intensidade do pico principal antes e depois de realizada a deconvolução pelo método do CGCA, da área total e da área do pico principal

\begin{tabular}{ccccccc}
\hline Irradiação & 1 & 2 & 3 & 4 & 5 & $\bar{\sigma}(\%)$ \\
\hline$\overline{\mathrm{M}}$ & 827,85 & 717,51 & 694,58 & 242,76 & 691,32 & \\
$\sigma_{\overline{\mathrm{M}}}$ & 113,01 & 81,65 & 91,32 & 149,86 & 95,29 & \\
$\sigma_{\overline{\mathrm{M}}}(\%)$ & 13,65 & 11,38 & 13,15 & 61,73 & 13,78 & 22,74 \\
\hline$\overline{\mathrm{M}_{\mathrm{pp}}}$ & 431,89 & 412,23 & 416,40 & 398,39 & 415,06 & \\
$\sigma_{\mathrm{M}_{\mathrm{pp}}}$ & 70,36 & 64,49 & 65,96 & 59,12 & 66,17 & \\
$\sigma_{\mathrm{M}_{\mathrm{pp}}}(\%)$ & 16,29 & 15,64 & 15,84 & 14,84 & 15,94 & 15,71 \\
\hline $\mathrm{M}_{\mathrm{ppd}}$ & 1,55 & 1,52 & 1,54 & 1,46 & 1,12 & \\
$\sigma_{\mathrm{M}_{\mathrm{ppd}}}$ & 0,24 & 0,22 & 0,24 & 0,26 & 0,11 & \\
$\sigma_{\mathrm{M}_{\mathrm{ppd}}}(\%)$ & 15,14 & 14,24 & 15,36 & 17,76 & 9,72 & 14,44 \\
\hline$\overline{\mathrm{A}_{\mathrm{t}}}$ & 898,43 & 709,18 & 714,06 & 712,30 & 647,18 & \\
$\sigma_{\mathrm{A}_{\mathrm{t}}}$ & 126,93 & 104,66 & 105,80 & 109,42 & 90,62 & \\
$\left.\sigma_{\mathrm{A}_{\mathrm{t}}} \%\right)$ & 14,13 & 14,76 & 14,82 & 15,36 & 14,00 & 14,61 \\
\hline$\overline{\mathrm{A}_{\mathrm{pp}}}$ & 705,11 & 610,65 & 617,33 & 602,99 & 348,04 & \\
$\sigma_{\mathrm{App}}$ & 119,61 & 94,40 & 98,09 & 98,19 & 45,53 & \\
$\sigma_{\mathrm{App}_{\mathrm{pp}}}(\%)$ & 16,96 & 15,46 & 15,89 & 16,28 & 13,08 & 15,54 \\
\hline & & & & & & \\
\hline
\end{tabular}




\subsection{Mínima Dose Detectável}

A mínima dose detectável, $D_{L D L}$, foi calculada utilizando a equação 16 e os resultados apresentados na tabela 04 a seguir, utilizando os valores de emissão da intensidade do pico principal após a deconvolução.

Tabela 04 - Cálculo da dose mínima detectável, DLDL.

\begin{tabular}{cccccc}
\hline Irradiação & 1 & 2 & 3 & 4 & 5 \\
\hline$\sigma_{B G}$ & 1,218 & 3,533 & 1,681 & 1,446 & 0,803 \\
$\sigma_{L}$ & 0,235 & 0,216 & 0,237 & 0,259 & 0,109 \\
$\bar{M}$ & 1,553 & 1,520 & 1,545 & 1,339 & 1,119 \\
$D_{C}(\mathrm{mGy})$ & 8,084 & 8,084 & 8,084 & 8,084 & 8,084 \\
$\phi_{C}(\mathrm{mGy} / \mathrm{TL})$ & 0,005 & 0,005 & 0,005 & 0,006 & 0,007 \\
$\Delta \phi_{C}(\mathrm{mGy} / \mathrm{TL})$ & 0,001 & 0,001 & 0,001 & 0,001 & 0,001 \\
$D_{\mathrm{LDL}}(\mathrm{mGy})$ & 0,019 & 0,056 & 0,026 & 0,026 & 0,017 \\
\hline
\end{tabular}

em que $\sigma_{B G}$ é o desvio padrão do sinal de fundo calculado na tabela $01 ; \sigma_{L}$ é o desvio padrão das leituras de emissão TL; $\overline{\mathrm{M}}$ é o valor médio das leituras; $D_{C}$ é a dose de calibração; $\phi_{C}$ é o fator de calibração e $\Delta \phi_{C}$ é o erro relacionado ao fator de calibração. O valor médio de dose mínima detectável é 0,028 mGy, ou $28 \mu \mathrm{Gy}$.

\subsection{Reprodutibilidade}

A reprodutibilidade é calculada a partir dos coeficientes de variação SVI, RVI e DVI descritas no capítulo anterior. As tabelas 05 e 06 mostram o cálculo desses parâmetros utilizando os valores de emissão TL a partir da intensidade do pico principal após a deconvolução.

Tabela 05 - Cálculo do Índice de Variabilidade do Sistema (SVI).

\begin{tabular}{cc}
\hline$\overline{C V}$ & 0,193 \\
\hline$\% \overline{C V}$ & 19,281 \\
\hline
\end{tabular}

Tabela 06 - Cálculo do Índice de Variabilidade do Leitor (RVI).

\begin{tabular}{cccccccc}
\hline $\begin{array}{c}1^{\mathrm{a}} \\
\text { Leitura }\end{array}$ & $\begin{array}{c}2^{\mathrm{a}} \mathrm{a} \\
\text { Leitura }\end{array}$ & $\begin{array}{c}3^{\mathrm{a}} \mathrm{a} \\
\text { Leitura }\end{array}$ & $\begin{array}{c}4^{\mathrm{a}} \\
\text { Leitura }\end{array}$ & $\begin{array}{c}5^{\mathrm{a}} \\
\text { Leitura }\end{array}$ & Mean & SD & CV(\%) \\
\hline 1,553 & 1,520 & 1,545 & 1,339 & 1,119 & 1,415 & 0,1875 & 13,25 \\
\hline
\end{tabular}


Como já discutimos anteriormente, o DVI é dado pela expressão:

$$
D V I=\sqrt{(S V I)^{2}-(R V I)^{2}}=\sqrt{(371,76)-(174,56)}=14,01 \%
$$

Ou seja, a variabilidade total do lote de dosímetros é $14,01 \%$, um valor maior que a recomendação do IEC[31], contudo é explicado pelo grande número de dosímetros no grupo e pode ser minimizado se for utilizado um fator de correção individual para cada TLD.

Assim, conclui-se que a dispersão das leituras de TL está principalmente associada à heterogeneidade do lote de dosímetros. Este resultado mostra que melhorias adicionais são necessárias no processo de fabricação, a fim de melhorar a reprodutibilidade na avaliação de dose com o TLD-100. 


\section{Conclusão}

Com base nas análises aplicadas no presente trabalho, o tratamento térmico rápido utilizado demonstrou um resultado adequado, tendo em vista ser um tratamento alternativo que comprovou sua eficácia. Além disso, o FOM para 48 dosímetros foi satisfatório e abaixo do valor recomendado, uma vez que o menor valor foi de 1,04 \%.

A implementação do método CGCA mostrou-se eficiente, pois a melhor resposta obtida de homogeneidade do grupo foi a partir da intensidade do pico principal após realizada a deconvolução com a análise do desvio padrão porcentual.

A dose mínima detectável apresentou um resultado adequado, de acordo com a referência, posto que o valor médio de $\mathrm{D}_{\mathrm{LDL}}$ foi de $28 \mu \mathrm{Gy}$, como mostra a tabela 04 e reforçou o método empregado no trabalho. Já a reprodutibilidade do lote indicou uma alta porcentagem de variação, que pode ser reduzida empregando-se um fator de correção individual em cada dosímetro do grupo.

Sendo assim, a implementação e o uso da CGCA em dosimetria TL clínica pode possibilitar uma alta precisão, com melhor garantia da qualidade, requisito importante para medições em radiodiagnóstico e radioterapia. 


\section{Referências Bibliográficas}

[1] Y. Horowitz, "A Unified and Comprehensive Theory of the TL Dose Response of Thermoluminescent Systems Applied to LiF: Mg, Ti," in Microdosimetric Response Of Physical And Biological Systems To Low- And High-Let Radiations: Theory And Applications To Dosimetry, Elsevier, 2006.

[2] G. F. Knoll, Radiation Detection and Measurement. United Stades of America: John Wiley and Sons, 2010.

[3] N. Kristianpoller, R. Chen, and M. Israeli, "Dose dependence of thermoluminescence peaks," J. Phys. D. Appl. Phys., vol. 7, pp. 1063-1072, 1974.

[4] R. Chen, G. Fogel, and C. K. Lee, "A new look at the models of the superlinear dose dependence of thermoluminescence," Radiat. Prot. Dosimetry, vol. 65, pp. 63-67, 1996.

[5] R. Chen and A. Hag-Yahya, "Interpretation of very high activation energies and frequency factors in $\mathrm{tl}$ as being due to competition between centres," Radiat. Prot. Dosimetry, vol. 65, pp. 17-21, 1996.

[6] R. T. Devine, M. Moscovitch, and P. K. Blake, "The US Naval Dosimetry Centre Thermoluminescence Dosimetry System," Radiat. Prot. Dosimetry, vol. 30, pp. 231-236, 1990.

[7] Y. S. Horowitz and M. Moscovitch, "Highlights and Pitfalls of 20 Years of Application of Computerised Glow Curve Analysis To Thermoluminescence Research and Dosimetry," Radiat. Prot. Dosimetry, vol. 153, no. 1, pp. 1-22, 2012.

[8] F. H. Attix, Introduction to Radiological Physics and Radiation Dosimetry. Weinheim: WILEY-VCH Verlag GmbH \& Co. KGaA, 1986.

[9] E. Vano et al., "Dosimetric and radiation protection considerations based on some cases of patient skin injuries in interventional cardiology," Br. J. Radiol., vol. 71, no. 845, pp. 510-516, 1998. 
[10] K. Mohammadi, A. Moussavi Zarandi, H. Afarideh, and S. Shahmaleki, "Role of dopants in LiF:Mg,Cu, LiF:Mg,P and LiF:Mg,Cu,P detectors," J. Solid State Chem., vol. 202, pp. 282-290, 2013.

[11] S. W. S. McKeever and R. Chen, "Luminescence models," Radiat. Meas., vol. 27, no. 5-6, pp. 625-661, 1997.

[12] J. A. Harvey, M. L. Rodrigues, and K. J. Kearfott, "A computerized glow curve analysis (GCA) method for WinREMS thermoluminescent dosimeter data using MATLAB," Appl. Radiat. Isot., vol. 69, no. 9, pp. 1282-1286, 2011.

[13] J. Van Dam and G. Marinello, Methods for in vivo dosimetry in external radiotherapy. Brussel: Estro, 1994.

[14] J. R. Cameron, N. Suntharalingam, and G. N. Kenney, Thermoluminescent dosimetry. Madison: WI: University of Wisconsin, 1968.

[15] J. Zoetelief, H. W. Julius, and P. Christensen, "EUR 19604 -Recommendations for patient dosimetry in diagnostic radiology using TLD.," Luxemburg, 2000.

[16] A. F. Mckinlay, "Applications of TLD in medicine," in Applied thermoluminescence dosimetry, M. Oberhofe and A. Scharmann, Eds. Bristol: Adam Hilger, 1981, pp. 271-287.

[17] I. A. E. AGENCY, "Dosimetry in diagnostic radiology: an international code of practice - Technical Report Series No. 457," Vienna, 2007.

[18] C. Furetta and P.-S. Weng, Operational Thermoluminescence Dosimetry. World Scientific Publishing Co. Pte. Ltd., 1998.

[19] J. T. Randall and M. H. F. Wilkins, "Phosphorescence and electron traps. I. The study of trap distributions," R. Soc. London Proceedings. Ser. A Math. Phys. Sci., vol. 184, no. 999, pp. 365-389, 1945.

[20] M. O. Akpochafor, M. A. Aweda, Z. A. Ibitoye, and S. O. Adeneye, "Thermoluminescent dosimetry in clinical kilovoltage beams," Radiography, vol. 19, no. 4, pp. 326-330, 2013. 
[21] C. M. H. Driscoll, J. R. Barthe, M. Oberhofer, G. Busuoli, and C. Hickman, "Annealing Procedures for Commonly Used Radiothermoluminescent Materials," Radiat. Prot. Dosimetry, vol. 14, no. 1, pp. 17-32, 1986.

[22] J. T. Randall and M. H. F. Wilkins, "Phosphorescence and electron traps. II. The inter-pretation of long-period phosphorescence.," R. Soc. London Proceedings. Ser. A Math. Phys. Sci., vol. 184, no. 999, pp. 390-407, 1945.

[23] G. Kitis, J. M. Gómes-Ros, and J. W. N. Tuyn, "Thermoluminescence glow-curve deconvolution functions for first, second and general orders of kinetics.," J. Phys. D. Appl. Phys., vol. 31, no. 19, pp. 2636-2641, 1998.

[24] C. Furetta, Handbook of Thermoluminescence. Singapore: World Scientific Publishing Co. Pte. Ltd., 2003.

[25] V. Pagonis, G. Kitis, and C. Furetta, Numerical and practical exercises in thermoluminescence. 2006.

[26] A. F. Mckinlay, Thermoluminescent Dosimetry, №5. Bristol:Adam Hilger, 1981.

[27] C. M. H. Driscoll, Fundamental Aspects of TLD Materials, Conference. London: HPA, 1984.

[28] B. Wall, R. Harryson, and F. Spiers, Patient Dosimetry Techniques in Diagnostic Radiology. IPEM, 1988.

[29] K. Burke and D. Sutton, "Optimization and deconvolution of lithium fluoride TLD100 in diagnostic radiology," Br. J. Radiol., vol. 70, no. MAR., pp. 261-271, 1997.

[30] M. A. K. Abdelhalim and A. El-t, "Assessment an accurate TL dosimeter recommended for patients and staff working in field of radiation: The physical properties of different kinds of TL dosimeters ASSESSMENT AN ACCURATE TL DOSIMETER RECOMMENDED FOR PATIENTS AND STAFF WORKING IN FIELD OF RADIATION: THE PHYSICAL PROPERTIES OF DIFFERENT KINDS OF TL," no. April 2015, 2014.

[31] B. A. Ademoh, "Assessment Of Characteristics Of Thermoluminescence Dosimetry (TLD) System Used in Centre for Energy Research and Training 
(CERT)," 2008.

[32] L. L. Campos, "Termoluminescência de materiais e sua aplicação em dosimetria da radiação," Cerâmica, vol. 44, no. 290, pp. 244-251, Dec. 1998.

[33] W. P. M. Mayles, S. Heisig, and H. M. O. Mayles, "Treatment verification and in vivo dosimetry.," in Radiotherapy physics: in practice., 2nd ed., J. R. WILLIAMS and D. I. THWAITES, Eds. New York: NY: Oxford, 2000, pp. 220-246.

[34] H. Gfirtner and G. Schenk, "Low Dose LiF Thermoluminescence Dosimetry for use in Diagnostic Radiology," Radiat. Prot. Dosim., vol. 43, no. 1/4, pp. 171-174, 992.

[35] M. J. Toivonen, "Improving the Accuracy of TLD Systems in Clinical Applications," Radiat. Prot. Dosimetry, vol. 47, no. 1/4, pp. 497-503, 1993.

[36] JCGM, "Avaliação de dados de medição — Guia para a expressão de incerteza de medição," Inmetro, vol. 1, p. 126, 2008. 


\section{APÊNDICE 01}

Tabela - Valores do sinal de fundo $\mathrm{M}_{0}$ dos dosímetros para cada ciclo.

\begin{tabular}{|c|c|c|c|c|c|}
\hline $\begin{array}{l}\text { Ciclo } \\
\text { Dosímetro }\end{array}$ & 1 & 2 & 3 & 4 & 5 \\
\hline 1 & 0,336 & 0,244 & 0,165 & 0,094 & 0,232 \\
\hline 2 & 0,203 & 0,211 & 0,221 & 0,085 & 0,277 \\
\hline 3 & 0,331 & 0,179 & 0,191 & 0,076 & 0,211 \\
\hline 4 & 0,138 & 0,165 & 0,197 & 0,056 & 0,135 \\
\hline 5 & 0,288 & 0,221 & 0,147 & 0,079 & 0,189 \\
\hline 6 & 0,347 & 0,191 & 0,053 & 0,114 & 0,216 \\
\hline 7 & 0,169 & 0,197 & 0,173 & 0,094 & 0,154 \\
\hline 8 & 0,310 & 0,147 & 0,109 & 0,095 & 0,230 \\
\hline 9 & 0,227 & 0,176 & 0,115 & 0,667 & 0,147 \\
\hline 10 & 0,191 & 0,273 & 0,656 & 0,053 & 0,127 \\
\hline 11 & 0,755 & 0,212 & 0,197 & 0,173 & 0,145 \\
\hline 12 & 0,199 & 0,213 & 0,169 & 0,109 & 0,241 \\
\hline 13 & 0,189 & 0,190 & 0,310 & 0,115 & 0,125 \\
\hline 14 & 0,352 & 0,262 & 0,227 & 0,656 & 0,135 \\
\hline 15 & 0,168 & 0,194 & 0,191 & 0,197 & 0,097 \\
\hline 16 & 0,428 & 0,223 & 0,755 & 0,644 & 0,137 \\
\hline 17 & 0,457 & 0,230 & 0,199 & 0,347 & 0,176 \\
\hline 18 & 0,239 & 0,273 & 0,189 & 0,188 & 0,154 \\
\hline 19 & 0,361 & 0,243 & 0,352 & 0,158 & 0,257 \\
\hline 20 & 0,342 & 0,191 & 0,168 & 0,163 & 0,133 \\
\hline 21 & 0,240 & 0,131 & 0,428 & 0,190 & 0,141 \\
\hline 22 & 0,206 & 0,877 & 0,457 & 0,174 & 0,542 \\
\hline 23 & 0,174 & 0,554 & 0,239 & 0,509 & 0,149 \\
\hline 24 & 0,386 & 0,888 & 0,237 & 0,440 & 0,233 \\
\hline 25 & 0,237 & 1,173 & 0,303 & 0,200 & 0,190 \\
\hline 26 & 0,303 & 0,529 & 0,362 & 0,172 & 0,162 \\
\hline 27 & 0,362 & 0,778 & 0,221 & 0,246 & 0,277 \\
\hline 28 & 0,221 & 0,491 & 0,278 & 0,182 & 0,150 \\
\hline 29 & 0,278 & 0,441 & 0,525 & 0,205 & 0,142 \\
\hline 30 & 0,525 & 0,891 & 0,356 & 0,177 & 0,137 \\
\hline 31 & 0,356 & 0,237 & 0,888 & 0,189 & 0,252 \\
\hline 32 & 0,523 & 0,190 & 1,173 & 0,366 & 0,219 \\
\hline 33 & 0,390 & 0,139 & 0,529 & 0,203 & 0,176 \\
\hline 34 & 0,393 & 0,147 & 0,778 & 0,405 & 0,188 \\
\hline 35 & 0,340 & 0,148 & 0,491 & 0,348 & 0,163 \\
\hline 36 & 0,312 & 0,113 & 0,441 & 0,183 & 0,143 \\
\hline 37 & 0,223 & 0,091 & 0,891 & 0,225 & 0,328 \\
\hline 38 & 0,336 & 0,223 & 0,246 & 0,217 & 0,215 \\
\hline
\end{tabular}


Continuação

\begin{tabular}{|c|c|c|c|c|c|}
\hline $\begin{array}{l}\text { Ciclo } \\
\text { Dosímetro }\end{array}$ & 1 & 2 & 3 & 4 & 5 \\
\hline 39 & 0,441 & 0,183 & 0,182 & 0,223 & 0,236 \\
\hline 40 & 0,409 & 0,110 & 0,205 & 0,149 & 0,195 \\
\hline 41 & 0,272 & 0,130 & 0,177 & 0,220 & 0,178 \\
\hline 42 & 0,464 & 0,108 & 0,189 & 0,255 & 0,153 \\
\hline 43 & 0,217 & 0,097 & 0,366 & 0,216 & 0,232 \\
\hline 44 & 0,334 & 0,132 & 0,203 & 0,224 & 0,136 \\
\hline 45 & 0,529 & 0,186 & 0,405 & 0,399 & 0,317 \\
\hline 46 & 0,476 & 0,147 & 0,139 & 0,361 & 0,420 \\
\hline 47 & 0,366 & 0,111 & 0,147 & 0,581 & 0,175 \\
\hline 48 & 0,230 & 0,174 & 0,148 & 0,431 & 0,276 \\
\hline 49 & 0,155 & 0,119 & 0,113 & 0,139 & 0,121 \\
\hline 50 & 0,368 & 0,143 & 0,091 & 0,342 & 0,237 \\
\hline 51 & 0,180 & 0,120 & 0,223 & 0,143 & 0,332 \\
\hline 52 & 0,171 & 0,252 & 0,183 & 0,194 & 0,165 \\
\hline 53 & 0,116 & 0,108 & 0,110 & 0,143 & 0,179 \\
\hline 54 & 0,155 & 0,096 & 0,130 & 0,164 & 0,297 \\
\hline 55 & 0,222 & 0,078 & 0,149 & 0,117 & 0,139 \\
\hline 56 & 0,114 & 0,090 & 0,220 & 0,154 & 0,214 \\
\hline 57 & 0,145 & 0,080 & 0,255 & 0,152 & 0,541 \\
\hline 58 & 0,179 & 0,161 & 0,216 & 0,110 & 0,180 \\
\hline 59 & 0,263 & 0,124 & 0,224 & 0,112 & 0,151 \\
\hline 60 & 0,173 & 0,120 & 0,399 & 0,111 & 0,113 \\
\hline 61 & 0,298 & 0,082 & 0,361 & 0,099 & 0,187 \\
\hline 62 & 0,120 & 0,086 & 0,581 & 0,136 & 0,103 \\
\hline 63 & 0,133 & 0,069 & 0,431 & 0,129 & 0,201 \\
\hline 64 & 0,088 & 0,138 & 0,139 & 0,132 & 0,149 \\
\hline 65 & 0,124 & 0,126 & 0,441 & 0,830 & 0,171 \\
\hline 66 & 0,184 & 0,084 & 0,409 & 0,372 & 0,213 \\
\hline 67 & 0,185 & 0,097 & 0,272 & 0,308 & 0,108 \\
\hline 68 & 0,153 & 0,093 & 0,464 & 0,187 & 0,139 \\
\hline 69 & 0,162 & 0,083 & 0,217 & 0,179 & 0,230 \\
\hline 70 & 0,236 & 0,153 & 0,334 & 0,192 & 0,225 \\
\hline 71 & 0,224 & 0,090 & 0,529 & 0,231 & 0,172 \\
\hline 72 & 0,374 & 0,143 & 0,476 & 0,219 & 0,114 \\
\hline 73 & 0,199 & 0,118 & 0,366 & 0,320 & 0,138 \\
\hline 74 & 0,109 & 0,163 & 0,230 & 0,193 & 0,331 \\
\hline 75 & 0,175 & 0,140 & 0,155 & 0,315 & 0,218 \\
\hline 76 & 0,095 & 0,103 & 0,255 & 0,212 & 0,114 \\
\hline 77 & 0,109 & 0,086 & 0,216 & 0,162 & 0,101 \\
\hline 78 & 0,216 & 0,140 & 0,224 & 0,119 & 0,107 \\
\hline 79 & 0,083 & 0,074 & 0,399 & 0,126 & 0,113 \\
\hline
\end{tabular}


Continuação

\begin{tabular}{|c|c|c|c|c|c|}
\hline Dosímetro & 1 & 2 & 3 & 4 & 5 \\
\hline 80 & 0,227 & 0,127 & 0,361 & 0,430 & 0,160 \\
\hline 81 & 0,205 & 0,113 & 0,581 & 0,315 & 0,245 \\
\hline 82 & 0,167 & 0,192 & 0,431 & 0,303 & 0,157 \\
\hline 83 & 0,211 & 0,223 & 0,139 & 0,480 & 0,322 \\
\hline 84 & 0,096 & 0,109 & 0,342 & 0,218 & 0,234 \\
\hline 85 & 0,130 & 0,137 & 0,120 & 0,292 & 0,224 \\
\hline 86 & 0,135 & 0,170 & 0,082 & 0,426 & 0,225 \\
\hline 87 & 0,164 & 0,097 & 0,086 & 0,211 & 0,173 \\
\hline 88 & 0,153 & 0,136 & 0,069 & 0,252 & 0,260 \\
\hline 89 & 0,194 & 0,201 & 0,138 & 0,243 & 0,223 \\
\hline 90 & 0,140 & 0,179 & 0,126 & 0,107 & 0,189 \\
\hline 91 & 0,190 & 0,168 & 0,084 & 0,267 & 0,207 \\
\hline 92 & 0,184 & 0,135 & 0,097 & 0,181 & 0,150 \\
\hline 93 & 0,141 & 0,164 & 0,093 & 0,219 & 0,245 \\
\hline 94 & 0,075 & 0,140 & 0,083 & 0,168 & 0,202 \\
\hline 95 & 0,251 & 0,097 & 0,094 & 0,282 & 0,395 \\
\hline 96 & 0,156 & 0,128 & 0,085 & 0,202 & 0,225 \\
\hline 97 & 0,180 & 0,084 & 0,076 & 0,491 & 0,244 \\
\hline 98 & 0,112 & 0,162 & 0,056 & 0,198 & 0,231 \\
\hline 99 & 0,157 & 0,210 & 0,079 & 0,241 & 0,207 \\
\hline 100 & 0,140 & 0,172 & 0,114 & 0,145 & 0,162 \\
\hline
\end{tabular}




\section{APÊNDICE 02}

Tabela - Parâmetro FOM calculado a partir do método CGCA.

\begin{tabular}{|c|c|c|c|c|c|}
\hline $\begin{array}{l}\text { Irradiação } \\
\text { Dosímetro }\end{array}$ & 1 & 2 & 3 & 4 & 5 \\
\hline 1 & 3,724 & 1,319 & 1,595 & 1,615 & 2,530 \\
\hline 2 & 1,740 & 2,336 & 1,618 & 1,556 & 2,343 \\
\hline 3 & 5,126 & 2,183 & 2,860 & 1,919 & 3,891 \\
\hline 4 & 3,456 & 3,184 & 3,157 & 1,673 & 5,316 \\
\hline 5 & 5,177 & 2,229 & 3,563 & 1,893 & 2,868 \\
\hline 6 & 5,431 & 6,183 & 2,682 & 2,232 & 2,329 \\
\hline 7 & 5,320 & 3,489 & 1,500 & 2,050 & 4,555 \\
\hline 8 & 4,572 & 5,331 & 2,565 & 1,545 & 2,921 \\
\hline 9 & 5,343 & 1,803 & 3,541 & 3,881 & 1,801 \\
\hline 10 & 5,044 & 2,005 & 3,907 & 4,742 & 2,165 \\
\hline 11 & 4,237 & 1,470 & 2,763 & 2,063 & 2,879 \\
\hline 12 & 4,758 & 2,635 & 3,481 & 2,889 & 4,122 \\
\hline 13 & 3,427 & 3,481 & 2,919 & 4,755 & 1,956 \\
\hline 14 & 1,471 & 3,806 & 4,428 & 3,900 & 2,277 \\
\hline 15 & 2,962 & 1,464 & 4,607 & 2,386 & 1,813 \\
\hline 16 & 6,562 & 3,020 & 1,639 & 7,446 & 2,422 \\
\hline 17 & 6,665 & 2,142 & 2,259 & 2,668 & 3,201 \\
\hline 18 & 5,238 & 3,453 & 1,494 & 2,583 & 4,029 \\
\hline 19 & 4,709 & 3,965 & 3,164 & 2,398 & 4,999 \\
\hline 20 & 5,960 & 1,674 & 3,738 & 1,989 & 5,882 \\
\hline 21 & 1,725 & 1,728 & 3,736 & 4,150 & 6,516 \\
\hline 22 & 5,816 & 2,396 & 1,366 & 2,352 & 4,644 \\
\hline 23 & 6,407 & 4,394 & 3,628 & 4,667 & 4,608 \\
\hline 24 & 6,642 & 2,984 & 1,420 & 4,440 & 2,769 \\
\hline 25 & 3,184 & 2,527 & 4,356 & 2,753 & 3,369 \\
\hline 26 & 5,336 & 5,367 & 3,251 & 4,360 & 3,321 \\
\hline 27 & 5,492 & 3,505 & 1,782 & 4,974 & 2,863 \\
\hline 28 & 5,079 & 3,945 & 1,752 & 2,539 & 2,664 \\
\hline 29 & 5,612 & 4,130 & 2,739 & 1,705 & 4,224 \\
\hline 30 & 2,983 & 2,431 & 3,091 & 3,426 & 4,547 \\
\hline 31 & 5,134 & 1,509 & 1,687 & 1,998 & 2,464 \\
\hline 32 & 2,703 & 2,583 & 3,629 & 1,518 & 3,829 \\
\hline 33 & 2,227 & 2,330 & 3,727 & 2,082 & 4,254 \\
\hline 34 & 1,736 & 2,976 & 1,834 & 3,213 & 3,767 \\
\hline 35 & 2,519 & 2,018 & 2,035 & 2,364 & 3,601 \\
\hline 36 & 5,614 & 2,548 & 2,045 & 1,923 & 3,712 \\
\hline 37 & 2,670 & 2,078 & 2,855 & 1,526 & 3,970 \\
\hline 38 & 5,401 & 1,714 & 3,043 & 4,787 & 5,064 \\
\hline
\end{tabular}


Continuação

\begin{tabular}{|c|c|c|c|c|c|}
\hline $\begin{array}{l}\text { Irradiação } \\
\text { Dosímetro }\end{array}$ & 1 & 2 & 3 & 4 & 5 \\
\hline 39 & 6,209 & 4,167 & 1,412 & 1,850 & 5,788 \\
\hline 40 & 3,008 & 3,267 & 1,402 & 3,044 & 2,086 \\
\hline 41 & 6,008 & 3,616 & 2,716 & 2,416 & 2,845 \\
\hline 42 & 2,804 & 1,745 & 3,371 & 3,531 & 2,431 \\
\hline 43 & 4,471 & 3,428 & 2,841 & 2,391 & 4,260 \\
\hline 44 & 3,918 & 6,727 & 1,659 & 3,368 & 4,293 \\
\hline 45 & 1,797 & 2,134 & 2,018 & 2,048 & 3,699 \\
\hline 46 & 1,791 & 1,638 & 3,368 & 5,042 & 4,410 \\
\hline 47 & 1,476 & 1,652 & 2,334 & 3,590 & 4,737 \\
\hline 48 & 2,844 & 1,433 & 3,297 & 5,425 & 4,168 \\
\hline 49 & 5,880 & 1,492 & 3,695 & 3,068 & 8,205 \\
\hline 50 & 6,062 & 4,014 & 3,053 & 3,233 & 2,974 \\
\hline 51 & 5,147 & 2,004 & 1,321 & 4,564 & 1,289 \\
\hline 52 & 2,853 & 1,424 & 1,743 & 1,871 & 8,689 \\
\hline 53 & 1,310 & 1,300 & 3,833 & 5,956 & 1,153 \\
\hline 54 & 4,497 & 2,556 & 4,982 & 1,705 & 9,705 \\
\hline 55 & 4,842 & 3,127 & 3,026 & 5,221 & 8,407 \\
\hline 56 & 5,107 & 3,016 & 4,382 & 1,724 & 9,327 \\
\hline 57 & 4,945 & 1,762 & 1,402 & 2,378 & 1,134 \\
\hline 58 & 5,339 & 1,655 & 1,937 & 5,052 & 6,925 \\
\hline 59 & 3,987 & 1,490 & 2,610 & 1,498 & 7,282 \\
\hline 60 & 3,954 & 3,928 & 1,836 & 2,121 & 9,278 \\
\hline 61 & 4,275 & 4,967 & 2,897 & 3,018 & 9,730 \\
\hline 62 & 1,885 & 2,898 & 3,455 & 4,823 & 8,828 \\
\hline 63 & 4,295 & 1,553 & 2,659 & 2,090 & 1,196 \\
\hline 64 & 2,282 & 3,604 & 1,959 & 8,310 & 8,522 \\
\hline 65 & 5,165 & 3,419 & 3,784 & 3,049 & 7,411 \\
\hline 66 & 2,769 & 1,260 & 6,808 & 7,149 & 1,287 \\
\hline 67 & 4,592 & 6,510 & 1,693 & 3,989 & 4,588 \\
\hline 68 & 2,374 & 3,304 & 2,348 & 2,572 & 8,047 \\
\hline 69 & 2,739 & 3,897 & 2,773 & 3,178 & 7,239 \\
\hline 70 & 5,614 & 6,568 & 3,779 & 8,465 & 9,052 \\
\hline 71 & 1,368 & 2,210 & 7,714 & 2,101 & 6,564 \\
\hline 72 & 6,101 & 7,716 & 2,825 & 1,934 & 6,570 \\
\hline 73 & 1,451 & 1,367 & 4,425 & 2,350 & 8,064 \\
\hline 74 & 4,545 & 3,588 & 2,638 & 5,851 & 8,913 \\
\hline 75 & 1,767 & 3,050 & 1,385 & 3,897 & 2,516 \\
\hline 76 & 4,776 & 2,759 & 1,552 & 4,945 & 2,272 \\
\hline 77 & 2,769 & 2,879 & 3,961 & 2,553 & 4,500 \\
\hline 78 & 4,083 & 6,683 & 5,212 & 3,674 & 3,776 \\
\hline 79 & 3,639 & 4,540 & 3,974 & 6,564 & 2,466 \\
\hline
\end{tabular}


Continuação

\begin{tabular}{|c|c|c|c|c|c|}
\hline $\begin{array}{l}\text { Irradiação } \\
\text { Dosímetro }\end{array}$ & 1 & 2 & 3 & 4 & 5 \\
\hline 80 & 1,389 & 1,685 & 4,434 & 4,695 & 1,210 \\
\hline 81 & 5,399 & 4,451 & 3,085 & 4,437 & 6,684 \\
\hline 82 & 4,323 & 1,370 & 2,972 & 4,751 & 4,706 \\
\hline 83 & 4,104 & 2,305 & 2,183 & 2,530 & 7,930 \\
\hline 84 & 1,369 & 1,376 & 1,350 & 4,847 & 9,793 \\
\hline 85 & 3,846 & 4,244 & 1,424 & 4,420 & 4,692 \\
\hline 86 & 1,351 & 2,721 & 1,857 & 4,217 & 1,043 \\
\hline 87 & 1,348 & 1,658 & 3,614 & 4,858 & 7,961 \\
\hline 88 & 1,280 & 1,608 & 1,853 & 3,084 & 3,379 \\
\hline 89 & 5,449 & 3,848 & 1,928 & 1,507 & 8,013 \\
\hline 90 & 1,686 & 1,553 & 2,136 & 3,675 & 7,766 \\
\hline 91 & 1,398 & 1,405 & 1,977 & 4,412 & 9,139 \\
\hline 92 & 1,354 & 2,174 & 1,615 & 1,666 & 7,900 \\
\hline 93 & 1,552 & 1,477 & 4,140 & 3,418 & 8,293 \\
\hline 94 & 1,210 & 2,039 & 1,989 & 3,308 & 9,079 \\
\hline 95 & 1,821 & 3,619 & 1,493 & 5,046 & 1,042 \\
\hline 96 & 1,798 & 4,374 & 4,601 & 4,641 & 7,764 \\
\hline 97 & 1,529 & 1,566 & 4,438 & 1,604 & 8,345 \\
\hline 98 & 1,537 & 4,238 & 2,671 & 4,338 & 7,958 \\
\hline 99 & 1,515 & 1,826 & 4,137 & 1,524 & 7,477 \\
\hline 100 & 1,816 & 1,874 & 1,393 & 2,180 & 6,750 \\
\hline
\end{tabular}




\section{APÊNDICE 03}

Tabela - Teste de homogeneidade do grupo de cem dosímetros a partir do valor médio (Ī) de emissão TL.

\begin{tabular}{|c|c|c|c|c|c|}
\hline $\begin{array}{l}\text { Irradiação } \\
\text { Dosímetro }\end{array}$ & 1 & 2 & 3 & 4 & 5 \\
\hline 1 & 766,54 & 808,61 & 602,36 & 94,25 & 600,85 \\
\hline 2 & 722,02 & 753,98 & 611,41 & 84,88 & 604,83 \\
\hline 3 & 759,68 & 724,60 & 629,69 & 75,70 & 594,45 \\
\hline 4 & 887,42 & 750,59 & 708,00 & 55,80 & 668,87 \\
\hline 5 & 806,60 & 766,07 & 648,35 & 79,29 & 608,31 \\
\hline 6 & 746,85 & 696,11 & 599,73 & 113,63 & 625,51 \\
\hline 7 & 717,34 & 682,30 & 598,18 & 93,59 & 570,72 \\
\hline 8 & 739,69 & 703,41 & 617,10 & 94,65 & 580,42 \\
\hline 9 & 626,21 & 568,42 & 509,91 & 666,85 & 490,87 \\
\hline 10 & 690,47 & 644,20 & 547,54 & 53,17 & 513,46 \\
\hline 11 & 746,42 & 683,38 & 637,75 & 173,48 & 610,48 \\
\hline 12 & 696,75 & 630,09 & 604,24 & 109,16 & 566,41 \\
\hline 13 & 696,86 & 576,83 & 561,19 & 114,98 & 537,45 \\
\hline 14 & 709,29 & 680,67 & 587,10 & 655,52 & 548,01 \\
\hline 15 & 681,62 & 690,74 & 570,53 & 196,85 & 532,51 \\
\hline 16 & 687,12 & 775,51 & 616,23 & 644,49 & 594,88 \\
\hline 17 & 751,80 & 878,69 & 664,83 & 346,60 & 692,18 \\
\hline 18 & 727,21 & 837,42 & 648,67 & 188,38 & 618,15 \\
\hline 19 & 774,52 & 828,43 & 655,97 & 158,16 & 614,15 \\
\hline 20 & 745,58 & 703,86 & 615,68 & 162,58 & 584,62 \\
\hline 21 & 839,49 & 787,14 & 696,38 & 190,22 & 688,84 \\
\hline 22 & 789,48 & 768,30 & 704,18 & 174,30 & 675,50 \\
\hline 23 & 789,94 & 741,08 & 682,67 & 508,99 & 696,07 \\
\hline 24 & 697,63 & 810,77 & 646,98 & 440,39 & 724,79 \\
\hline 25 & 796,15 & 706,42 & 645,29 & 200,22 & 644,64 \\
\hline 26 & 692,78 & 623,82 & 556,68 & 171,66 & 567,61 \\
\hline 27 & 743,07 & 701,10 & 661,21 & 246,24 & 609,24 \\
\hline 28 & 727,74 & 644,34 & 614,85 & 181,67 & 598,50 \\
\hline 29 & 736,21 & 630,99 & 605,48 & 205,30 & 589,22 \\
\hline 30 & 747,94 & 651,71 & 635,95 & 176,63 & 594,76 \\
\hline 31 & 685,05 & 587,59 & 651,28 & 188,88 & 641,45 \\
\hline 32 & 779,07 & 653,34 & 687,45 & 365,64 & 734,26 \\
\hline 33 & 783,43 & 651,30 & 692,03 & 202,80 & 721,89 \\
\hline 34 & 800,80 & 682,13 & 741,01 & 404,69 & 769,56 \\
\hline 35 & 765,34 & 647,23 & 701,65 & 348,10 & 771,36 \\
\hline 36 & 765,93 & 660,27 & 687,64 & 182,66 & 699,55 \\
\hline
\end{tabular}


Continuação

\begin{tabular}{|c|c|c|c|c|c|}
\hline $\begin{array}{l}\text { Irradiação } \\
\text { Dosímetro }\end{array}$ & 1 & 2 & 3 & 4 & 5 \\
\hline 37 & 705,80 & 617,94 & 600,18 & 224,74 & 643,24 \\
\hline 38 & 784,43 & 710,20 & 683,41 & 217,02 & 812,89 \\
\hline 39 & 828,08 & 669,49 & 637,13 & 637,13 & 692,61 \\
\hline 40 & 679,91 & 597,43 & 574,16 & 149,32 & 581,93 \\
\hline 41 & 680,63 & 552,88 & 583,10 & 220,02 & 573,30 \\
\hline 42 & 718,43 & 560,29 & 607,60 & 255,20 & 644,19 \\
\hline 43 & 747,72 & 636,60 & 646,63 & 216,42 & 669,91 \\
\hline 44 & 744,97 & 622,16 & 654,14 & 223,60 & 663,09 \\
\hline 45 & 789,66 & 705,54 & 705,88 & 398,78 & 800,17 \\
\hline 46 & 790,02 & 678,03 & 679,60 & 360,60 & 679,28 \\
\hline 47 & 822,67 & 729,80 & 695,09 & 580,97 & 695,61 \\
\hline 48 & 779,27 & 699,64 & 680,01 & 431,25 & 637,48 \\
\hline 49 & 977,33 & 816,85 & 776,25 & 139,12 & 757,17 \\
\hline 50 & 762,75 & 668,85 & 639,58 & 341,65 & 597,12 \\
\hline 51 & 982,25 & 783,16 & 822,63 & 143,34 & 831,81 \\
\hline 52 & 930,20 & 732,28 & 769,01 & 193,50 & 785,99 \\
\hline 53 & 950,55 & 747,75 & 787,28 & 142,60 & 823,06 \\
\hline 54 & 990,25 & 801,82 & 846,28 & 164,42 & 845,59 \\
\hline 55 & 1011,30 & 833,88 & 854,36 & 116,55 & 839,52 \\
\hline 56 & 986,65 & 818,27 & 875,56 & 153,71 & 826,17 \\
\hline 57 & 925,91 & 758,60 & 747,86 & 151,94 & 757,53 \\
\hline 58 & 936,83 & 785,48 & 752,94 & 109,72 & 755,97 \\
\hline 59 & 930,81 & 784,77 & 745,12 & 112,40 & 756,29 \\
\hline 60 & 850,35 & 714,71 & 671,94 & 111,34 & 673,02 \\
\hline 61 & 889,47 & 713,71 & 735,16 & 99,40 & 719,42 \\
\hline 62 & 885,68 & 699,53 & 723,97 & 135,66 & 733,86 \\
\hline 63 & 959,25 & 761,76 & 795,23 & 128,90 & 762,17 \\
\hline 64 & 939,74 & 756,33 & 805,01 & 131,76 & 795,64 \\
\hline 65 & 976,40 & 756,51 & 781,17 & 830,27 & 792,04 \\
\hline 66 & 937,80 & 790,18 & 753,44 & 372,28 & 785,96 \\
\hline 67 & 821,77 & 694,21 & 665,77 & 307,62 & 673,52 \\
\hline 68 & 943,44 & 821,35 & 757,26 & 186,64 & 761,53 \\
\hline 69 & 854,22 & 724,17 & 689,93 & 178,93 & 669,06 \\
\hline 70 & 955,19 & 816,42 & 776,95 & 191,80 & 758,94 \\
\hline 71 & 948,01 & 753,73 & 780,44 & 231,35 & 749,25 \\
\hline 72 & 933,89 & 722,72 & 748,37 & 218,74 & 744,46 \\
\hline 73 & 1006,58 & 747,75 & 776,53 & 319,75 & 789,41 \\
\hline 74 & 931,55 & 741,05 & 782,78 & 192,96 & 768,15 \\
\hline 75 & 708,43 & 580,84 & 577,45 & 314,61 & 584,02 \\
\hline 76 & 613,56 & 520,17 & 499,01 & 211,62 & 523,16 \\
\hline 77 & 570,21 & 488,43 & 466,47 & 162,07 & 490,25 \\
\hline
\end{tabular}


Continuação

\begin{tabular}{cccccc}
\cline { 1 - 5 } Irradiação & 1 & 2 & 3 & 4 & 5 \\
\cline { 2 - 6 } Dosímetro & 625,03 & 538,62 & 516,34 & 118,91 & 523,56 \\
78 & 609,82 & 512,96 & 527,91 & 125,80 & 488,83 \\
79 & 987,53 & 822,26 & 801,16 & 430,09 & 779,48 \\
80 & 948,93 & 778,28 & 767,05 & 315,01 & 753,14 \\
81 & 875,71 & 723,87 & 722,30 & 303,15 & 688,72 \\
82 & 966,35 & 789,05 & 798,73 & 480,22 & 798,27 \\
83 & 963,04 & 783,74 & 852,80 & 218,32 & 809,92 \\
84 & 1015,60 & 814,65 & 873,92 & 292,21 & 797,21 \\
85 & 960,92 & 783,96 & 767,66 & 425,75 & 787,71 \\
86 & 918,06 & 748,36 & 773,39 & 211,25 & 770,08 \\
87 & 901,69 & 745,74 & 775,86 & 251,68 & 734,58 \\
88 & 962,42 & 785,58 & 816,26 & 243,18 & 791,91 \\
89 & 991,75 & 792,48 & 770,01 & 106,64 & 758,94 \\
90 & 897,23 & 746,71 & 763,52 & 266,56 & 758,70 \\
91 & 922,96 & 749,07 & 748,42 & 180,99 & 767,83 \\
92 & 872,35 & 758,28 & 763,65 & 218,61 & 729,81 \\
93 & 907,56 & 766,16 & 774,81 & 168,19 & 780,73 \\
94 & 941,63 & 778,20 & 802,00 & 282,00 & 784,16 \\
95 & 886,74 & 757,66 & 783,25 & 202,33 & 782,75 \\
96 & 931,39 & 801,14 & 800,17 & 491,17 & 801,18 \\
97 & 914,18 & 772,53 & 760,24 & 197,73 & 791,45 \\
98 & 926,16 & 783,31 & 779,88 & 240,99 & 793,76 \\
99 & 856,02 & 771,72 & 722,54 & 145,33 & 731,28 \\
\hline 100 & & & & &
\end{tabular}




\section{APÊNDICE 04}

Tabela - Teste de homogeneidade do grupo de cem dosímetros a partir do valor da intensidade do pico principal de emissão $T L\left(M_{p p}\right)$.

\begin{tabular}{|c|c|c|c|c|c|}
\hline $\begin{array}{l}\text { Irradiação } \\
\text { Dosímetro }\end{array}$ & 1 & 2 & 3 & 4 & 5 \\
\hline 1 & 383,20 & 372,40 & 359,98 & 347,04 & 357,14 \\
\hline 2 & 360,10 & 325,00 & 346,48 & 320,60 & 342,02 \\
\hline 3 & 389,10 & 359,80 & 372,17 & 348,79 & 362,70 \\
\hline 4 & 476,60 & 432,70 & 448,47 & 415,15 & 430,68 \\
\hline 5 & 423,40 & 370,90 & 378,69 & 362,15 & 363,25 \\
\hline 6 & 373,90 & 357,40 & 347,53 & 339,92 & 371,70 \\
\hline 7 & 360,70 & 353,00 & 340,31 & 331,57 & 329,95 \\
\hline 8 & 370,20 & 357,80 & 350,90 & 349,81 & 333,93 \\
\hline 9 & 329,00 & 302,10 & 306,69 & 286,08 & 298,18 \\
\hline 10 & 339,20 & 337,10 & 308,40 & 433,31 & 287,93 \\
\hline 11 & 374,00 & 363,60 & 372,43 & 343,96 & 360,34 \\
\hline 12 & 346,40 & 324,60 & 346,33 & 317,94 & 339,86 \\
\hline 13 & 356,20 & 317,10 & 331,04 & 297,66 & 317,50 \\
\hline 14 & 362,80 & 343,40 & 341,14 & 331,22 & 335,57 \\
\hline 15 & 347,30 & 374,30 & 347,31 & 304,92 & 318,93 \\
\hline 16 & 348,00 & 339,00 & 346,86 & 358,44 & 346,56 \\
\hline 17 & 374,70 & 376,50 & 372,92 & 360,09 & 379,11 \\
\hline 18 & 370,10 & 370,80 & 344,88 & 330,32 & 358,23 \\
\hline 19 & 383,20 & 363,80 & 353,56 & 341,87 & 350,56 \\
\hline 20 & 376,20 & 366,00 & 367,49 & 359,38 & 346,03 \\
\hline 21 & 420,30 & 375,50 & 404,77 & 377,52 & 404,55 \\
\hline 22 & 401,10 & 377,70 & 400,89 & 377,26 & 381,08 \\
\hline 23 & 390,70 & 375,70 & 402,08 & 366,43 & 408,07 \\
\hline 24 & 354,90 & 357,50 & 355,32 & 398,20 & 364,56 \\
\hline 25 & 389,40 & 364,10 & 379,37 & 343,20 & 373,13 \\
\hline 26 & 356,10 & 347,10 & 335,93 & 314,84 & 342,90 \\
\hline 27 & 371,00 & 358,80 & 366,61 & 342,60 & 364,89 \\
\hline 28 & 366,80 & 371,30 & 360,80 & 347,06 & 354,74 \\
\hline 29 & 373,70 & 363,20 & 350,78 & 350,07 & 416,58 \\
\hline 30 & 371,00 & 368,00 & 355,90 & 346,05 & 359,27 \\
\hline 31 & 352,00 & 334,60 & 380,55 & 341,13 & 355,57 \\
\hline 32 & 387,70 & 376,40 & 397,48 & 362,60 & 400,98 \\
\hline 33 & 389,80 & 372,70 & 405,90 & 361,22 & 395,91 \\
\hline 34 & 411,00 & 390,90 & 415,93 & 360,10 & 408,95 \\
\hline 35 & 382,50 & 366,50 & 406,00 & 346,79 & 401,03 \\
\hline 36 & 390,50 & 387,20 & 399,00 & 370,33 & 394,68 \\
\hline 37 & 367,20 & 374,40 & 352,82 & 346,59 & 365,33 \\
\hline
\end{tabular}


Continuação

\begin{tabular}{|c|c|c|c|c|c|}
\hline $\begin{array}{l}\text { Jrradiação } \\
\text { Dosímetro }\end{array}$ & 1 & 2 & 3 & 4 & 5 \\
\hline 38 & 387,40 & 389,70 & 381,30 & 366,44 & 398,16 \\
\hline 39 & 432,80 & 391,00 & 364,37 & 381,75 & 375,81 \\
\hline 40 & 350,10 & 331,80 & 329,63 & 314,32 & 318,65 \\
\hline 41 & 347,40 & 321,50 & 354,41 & 319,38 & 336,62 \\
\hline 42 & 361,50 & 321,10 & 344,79 & 326,80 & 356,58 \\
\hline 43 & 383,20 & 362,70 & 381,38 & 345,82 & 372,67 \\
\hline 44 & 379,00 & 369,70 & 388,82 & 341,29 & 379,51 \\
\hline 45 & 393,10 & 398,40 & 431,13 & 365,72 & 417,85 \\
\hline 46 & 397,90 & 384,50 & 382,63 & 358,28 & 394,81 \\
\hline 47 & 424,20 & 415,20 & 408,66 & 382,96 & 415,20 \\
\hline 48 & 388,60 & 385,40 & 387,44 & 364,76 & 376,39 \\
\hline 49 & 514,10 & 493,90 & 489,79 & 470,42 & 471,28 \\
\hline 50 & 379,90 & 379,00 & 371,71 & 361,87 & 349,09 \\
\hline 51 & 511,60 & 485,20 & 514,10 & 475,43 & 532,63 \\
\hline 52 & 481,10 & 457,60 & 476,04 & 451,10 & 485,98 \\
\hline 53 & 500,80 & 468,00 & 491,13 & 467,97 & 496,62 \\
\hline 54 & 534,10 & 497,60 & 511,76 & 473,95 & 525,90 \\
\hline 55 & 537,20 & 522,20 & 526,97 & 478,05 & 520,10 \\
\hline 56 & 529,20 & 504,20 & 526,36 & 478,70 & 515,32 \\
\hline 57 & 484,20 & 461,00 & 453,94 & 435,92 & 475,14 \\
\hline 58 & 500,00 & 482,80 & 474,15 & 441,28 & 481,36 \\
\hline 59 & 498,10 & 477,80 & 467,41 & 456,51 & 474,58 \\
\hline 60 & 467,80 & 431,20 & 430,55 & 427,11 & 464,26 \\
\hline 61 & 470,10 & 447,70 & 447,34 & 429,94 & 460,67 \\
\hline 62 & 461,80 & 418,90 & 437,97 & 442,43 & 458,56 \\
\hline 63 & 512,60 & 474,20 & 498,01 & 453,35 & 472,86 \\
\hline 64 & 507,60 & 503,90 & 499,11 & 454,71 & 500,34 \\
\hline 65 & 561,20 & 470,10 & 468,13 & 452,35 & 484,00 \\
\hline 66 & 500,90 & 486,40 & 469,10 & 451,12 & 485,97 \\
\hline 67 & 450,20 & 434,70 & 425,02 & 413,20 & 406,17 \\
\hline 68 & 517,00 & 516,00 & 488,93 & 473,76 & 479,14 \\
\hline 69 & 456,50 & 449,60 & 432,57 & 418,29 & 415,31 \\
\hline 70 & 506,00 & 503,30 & 491,70 & 460,50 & 463,64 \\
\hline 71 & 486,10 & 452,20 & 470,81 & 468,26 & 461,31 \\
\hline 72 & 485,00 & 446,00 & 465,45 & 442,55 & 473,77 \\
\hline 73 & 526,80 & 475,20 & 488,43 & 472,87 & 495,70 \\
\hline 74 & 494,20 & 461,30 & 483,59 & 449,71 & 478,40 \\
\hline 75 & 347,90 & 345,80 & 335,10 & 324,02 & 342,04 \\
\hline 76 & 288,50 & 305,10 & 296,93 & 475,31 & 290,20 \\
\hline 77 & 374,80 & 289,80 & 297,18 & 361,09 & 478,16 \\
\hline 78 & 289,10 & 309,00 & 297,73 & 281,18 & 292,03 \\
\hline
\end{tabular}


Continuação

\begin{tabular}{|c|c|c|c|c|c|}
\hline $\begin{array}{l}\text { Jrradiação } \\
\text { Dosímetro }\end{array}$ & 1 & 2 & 3 & 4 & 5 \\
\hline 79 & 294,20 & 293,40 & 298,73 & 461,92 & 265,96 \\
\hline 80 & 536,90 & 503,00 & 488,16 & 386,51 & 485,59 \\
\hline 81 & 495,80 & 480,70 & 468,41 & 474,79 & 449,99 \\
\hline 82 & 460,20 & 431,70 & 455,40 & 442,89 & 420,42 \\
\hline 83 & 476,40 & 469,80 & 486,23 & 479,96 & 480,50 \\
\hline 84 & 495,90 & 458,40 & 505,75 & 468,81 & 468,81 \\
\hline 85 & 501,00 & 493,60 & 521,59 & 386,86 & 460,45 \\
\hline 86 & 500,90 & 481,80 & 481,00 & 473,38 & 488,11 \\
\hline 87 & 499,30 & 472,60 & 490,86 & 461,23 & 488,53 \\
\hline 88 & 482,60 & 449,20 & 469,77 & 468,64 & 464,59 \\
\hline 89 & 509,50 & 490,70 & 475,73 & 477,98 & 483,71 \\
\hline 90 & 520,10 & 480,40 & 460,47 & 481,43 & 477,16 \\
\hline 91 & 504,20 & 448,80 & 459,17 & 467,24 & 458,57 \\
\hline 92 & 511,70 & 452,50 & 453,34 & 473,46 & 474,24 \\
\hline 93 & 483,70 & 479,50 & 465,82 & 461,57 & 448,82 \\
\hline 94 & 505,70 & 528,10 & 473,55 & 474,69 & 487,15 \\
\hline 95 & 526,20 & 495,00 & 489,77 & 391,23 & 485,15 \\
\hline 96 & 500,00 & 477,50 & 566,68 & 467,17 & 488,05 \\
\hline 97 & 534,90 & 496,60 & 510,85 & 386,61 & 499,23 \\
\hline 98 & 522,90 & 485,40 & 461,59 & 383,10 & 492,22 \\
\hline 99 & 513,90 & 479,00 & 477,49 & 466,09 & 486,73 \\
\hline 100 & 473,20 & 485,50 & 443,90 & 460,85 & 456,83 \\
\hline
\end{tabular}




\section{APÊNDICE 05}

Tabela - Teste de homogeneidade do grupo de cem dosímetros a partir do valor da intensidade do pico principal de emissão $T L$ após a deconvolução $\left(\mathrm{M}_{\mathrm{ppd}}\right)$.

\begin{tabular}{cccccc}
\hline Irradiação & 1 & 2 & 3 & 4 & 5 \\
\hline Dosímetro & 1,140 & 1,268 & 1,255 & 1,227 & 1,091 \\
\hline 1 & 1,185 & 1,225 & 1,205 & 1,130 & 1,219 \\
3 & 1,813 & 1,256 & 1,173 & 1,235 & 1,029 \\
4 & 1,365 & 1,706 & 1,832 & 1,447 & 1,091 \\
5 & 1,126 & 1,376 & 1,697 & 1,289 & 1,091 \\
6 & 1,804 & 1,596 & 1,210 & 1,216 & 1,151 \\
7 & 1,661 & 1,636 & 1,289 & 1,156 & 1,209 \\
8 & 1,772 & 1,634 & 1,841 & 1,245 & 1,039 \\
9 & 1,784 & 1,234 & 1,716 & 1,028 & 1,028 \\
10 & 1,750 & 1,156 & 1,618 & 1,297 & 1,426 \\
11 & 1,391 & 1,265 & 1,267 & 1,226 & 1,049 \\
12 & 1,712 & 1,306 & 1,774 & 1,120 & 1,135 \\
13 & 1,279 & 1,782 & 1,363 & 1,081 & 1,161 \\
14 & 1,296 & 1,506 & 1,471 & 1,068 & 1,116 \\
15 & 1,244 & 1,339 & 1,675 & 1,017 & 1,195 \\
16 & 1,486 & 1,596 & 1,207 & 1,902 & 1,085 \\
17 & 1,698 & 1,321 & 1,864 & 1,041 & 1,091 \\
18 & 1,707 & 1,634 & 1,898 & 1,162 & 1,091 \\
19 & 1,700 & 1,843 & 1,547 & 1,200 & 1,021 \\
20 & 1,717 & 1,279 & 1,840 & 1,278 & 1,036 \\
21 & 1,452 & 1,251 & 1,892 & 1,020 & 1,091 \\
22 & 1,585 & 1,164 & 1,426 & 1,311 & 1,091 \\
23 & 1,631 & 1,451 & 1,406 & 1,841 & 1,091 \\
24 & 1,405 & 1,606 & 1,220 & 1,261 & 1,090 \\
25 & 1,416 & 1,281 & 1,834 & 1,206 & 1,091 \\
26 & 1,336 & 1,279 & 1,614 & 1,283 & 1,067 \\
27 & 1,765 & 1,636 & 1,226 & 1,214 & 1,091 \\
28 & 1,885 & 1,634 & 1,207 & 1,255 & 1,091 \\
29 & 1,693 & 1,843 & 1,809 & 1,262 & 1,091 \\
30 & 1,661 & 1,169 & 1,874 & 1,339 & 1,072 \\
31 & 1,868 & 1,217 & 1,216 & 1,216 & 1,080 \\
32 & 1,269 & 1,364 & 1,740 & 1,292 & 1,091 \\
33 & 1,423 & 1,332 & 1,284 & 1,210 & 1,091 \\
34 & 1,446 & 1,706 & 1,473 & 1,305 & 1,091 \\
35 & 1,237 & 1,244 & 1,433 & 1,070 & 1,091 \\
36 & 1,889 & 1,129 & 1,384 & 1,300 & 1,091 \\
37 & 1,321 & 1,259 & 1,341 & 1,208 & 1,390 \\
\hline & & Continua & & & \\
& & & & &
\end{tabular}


Continuação

\begin{tabular}{|c|c|c|c|c|c|}
\hline $\begin{array}{l}\text { Irradiação } \\
\text { Dosímetro }\end{array}$ & 1 & 2 & 3 & 4 & 5 \\
\hline 38 & 1,827 & 1,239 & 1,820 & 1,650 & $\overline{1,091}$ \\
\hline 39 & 1,574 & 1,430 & 1,284 & 1,344 & 1,134 \\
\hline 40 & 1,141 & 1,836 & 1,110 & 1,188 & 1,100 \\
\hline 41 & 1,868 & 1,649 & 1,370 & 1,011 & 1,246 \\
\hline 42 & 1,174 & 1,136 & 1,824 & 1,077 & 1,270 \\
\hline 43 & 1,232 & 1,498 & 1,364 & 1,068 & 1,091 \\
\hline 44 & 1,814 & 1,688 & 1,344 & 1,005 & 1,091 \\
\hline 45 & 1,362 & 1,200 & 1,405 & 1,279 & 1,091 \\
\hline 46 & 1,359 & 1,292 & 1,517 & 1,424 & 1,878 \\
\hline 47 & 1,491 & 1,357 & 1,172 & 1,159 & 1,091 \\
\hline 48 & 1,329 & 1,250 & 1,848 & 1,811 & 1,091 \\
\hline 49 & 1,213 & 1,585 & 1,189 & 1,741 & 1,091 \\
\hline 50 & 1,419 & 1,657 & 1,544 & 1,402 & 1,091 \\
\hline 51 & 1,863 & 1,716 & 1,807 & 1,012 & 1,091 \\
\hline 52 & 1,748 & 1,782 & 1,626 & 1,596 & 1,091 \\
\hline 53 & 1,777 & 1,506 & 1,792 & 1,035 & 1,091 \\
\hline 54 & 1,444 & 1,688 & 1,853 & 1,677 & 1,091 \\
\hline 55 & 1,460 & 1,596 & 1,436 & 1,087 & 1,091 \\
\hline 56 & 1,207 & 1,433 & 1,835 & 1,588 & 1,091 \\
\hline 57 & 1,126 & 1,634 & 1,612 & 1,654 & 1,091 \\
\hline 58 & 1,210 & 1,843 & 1,686 & 1,610 & 1,091 \\
\hline 59 & 1,407 & 1,657 & 1,708 & 1,632 & 1,091 \\
\hline 60 & 1,308 & 1,716 & 1,536 & 1,362 & 1,091 \\
\hline 61 & 1,889 & 1,782 & 1,640 & 1,198 & 1,091 \\
\hline 62 & 1,616 & 1,698 & 1,267 & 1,731 & 1,091 \\
\hline 63 & 1,475 & 1,688 & 1,421 & 1,618 & 1,091 \\
\hline 64 & 1,776 & 1,596 & 1,657 & 1,014 & 1,091 \\
\hline 65 & 1,315 & 1,161 & 1,194 & 1,773 & 1,091 \\
\hline 66 & 1,791 & 1,634 & 1,630 & 1,054 & 1,091 \\
\hline 67 & 1,415 & 1,843 & 1,481 & 1,097 & 1,091 \\
\hline 68 & 1,649 & 1,413 & 1,530 & 1,431 & 1,091 \\
\hline 69 & 1,453 & 1,636 & 1,125 & 1,514 & 1,091 \\
\hline 70 & 1,289 & 1,634 & 1,763 & 1,737 & 1,091 \\
\hline 71 & 1,677 & 1,843 & 1,824 & 1,660 & 1,091 \\
\hline 72 & 1,545 & 1,585 & 1,767 & 1,599 & 1,091 \\
\hline 73 & 1,754 & 1,876 & 1,211 & 1,669 & 1,091 \\
\hline 74 & 1,250 & 1,127 & 1,251 & 1,827 & 1,091 \\
\hline 75 & 1,140 & 1,403 & 1,187 & 1,048 & 1,269 \\
\hline 76 & 1,745 & 1,543 & 1,791 & 1,044 & 1,054 \\
\hline 77 & 1,212 & 1,149 & 1,547 & 1,799 & 1,067 \\
\hline 78 & 1,224 & 1,455 & 1,588 & 1,028 & 1,136 \\
\hline
\end{tabular}


Continuação

\begin{tabular}{|c|c|c|c|c|c|}
\hline $\begin{array}{l}\text { Irradiação } \\
\text { Dosímetro }\end{array}$ & 1 & 2 & 3 & 4 & 5 \\
\hline 79 & 1,263 & 1,606 & 1,213 & 1,321 & $\overline{1,064}$ \\
\hline 80 & 1,800 & 1,688 & 1,796 & 1,186 & 1,091 \\
\hline 81 & 1,790 & 1,596 & 1,158 & 1,198 & 1,091 \\
\hline 82 & 1,659 & 1,636 & 1,844 & 1,246 & 1,091 \\
\hline 83 & 1,806 & 1,634 & 1,569 & 1,403 & 1,091 \\
\hline 84 & 1,768 & 1,843 & 1,806 & 1,007 & 1,091 \\
\hline 85 & 1,700 & 1,585 & 1,843 & 1,079 & 1,530 \\
\hline 86 & 1,756 & 1,657 & 1,706 & 1,365 & 1,091 \\
\hline 87 & 1,768 & 1,716 & 1,246 & 1,067 & 1,091 \\
\hline 88 & 1,657 & 1,455 & 1,642 & 1,301 & 1,349 \\
\hline 89 & 1,781 & 1,206 & 1,715 & 1,717 & 1,091 \\
\hline 90 & 1,743 & 1,688 & 1,608 & 1,179 & 1,091 \\
\hline 91 & 1,659 & 1,596 & 1,648 & 1,736 & 1,091 \\
\hline 92 & 1,821 & 1,636 & 1,610 & 1,706 & 1,091 \\
\hline 93 & 1,663 & 1,634 & 1,599 & 1,180 & 1,091 \\
\hline 94 & 1,783 & 1,843 & 1,693 & 1,722 & 1,091 \\
\hline 95 & 1,824 & 1,585 & 1,738 & 1,514 & 1,091 \\
\hline 96 & 1,701 & 1,657 & 1,737 & 1,013 & 1,091 \\
\hline 97 & 1,790 & 1,716 & 1,770 & 1,755 & 1,091 \\
\hline 98 & 1,792 & 1,782 & 1,626 & 1,729 & 1,091 \\
\hline 99 & 1,714 & 1,573 & 1,687 & 1,674 & 1,091 \\
\hline 100 & 1,612 & 1,725 & 1,560 & 1,555 & 1,091 \\
\hline
\end{tabular}




\section{APÊNDICE 06}

Tabela - Teste de homogeneidade do grupo de cem dosímetros a partir do valor da área total $\left(A_{t}\right)$ da emissão TL após a deconvolução.

\begin{tabular}{|c|c|c|c|c|c|}
\hline $\begin{array}{l}\text { Irradiação } \\
\text { Dosímetro }\end{array}$ & 1 & 2 & 3 & 4 & 5 \\
\hline 1 & 829,39 & 608,58 & 611,90 & 633,02 & 599,56 \\
\hline 2 & 756,25 & 555,59 & 587,87 & 575,86 & 565,47 \\
\hline 3 & 824,31 & 623,53 & 651,95 & 633,24 & 376,18 \\
\hline 4 & 969,01 & 728,31 & 755,55 & 740,29 & 700,23 \\
\hline 5 & 863,76 & 628,65 & 663,66 & 650,02 & 614,85 \\
\hline 6 & 813,01 & 576,22 & 602,53 & 611,12 & 615,88 \\
\hline 7 & 772,26 & 604,36 & 595,85 & 598,98 & 546,42 \\
\hline 8 & 795,27 & 567,94 & 618,55 & 614,49 & 587,30 \\
\hline 9 & 683,67 & 528,68 & 526,91 & 538,24 & 514,18 \\
\hline 10 & 737,93 & 577,45 & 563,35 & 589,94 & 534,31 \\
\hline 11 & 826,61 & 602,78 & 636,49 & 612,94 & 613,17 \\
\hline 12 & 743,11 & 564,93 & 608,04 & 589,44 & 565,14 \\
\hline 13 & 750,52 & 539,26 & 583,78 & 526,22 & 565,29 \\
\hline 14 & 758,59 & 590,24 & 583,70 & 594,51 & 571,01 \\
\hline 15 & 735,20 & 649,82 & 577,45 & 562,84 & 564,90 \\
\hline 16 & 740,26 & 579,67 & 589,31 & 576,82 & 578,19 \\
\hline 17 & 823,96 & 639,14 & 655,43 & 683,06 & 623,69 \\
\hline 18 & 781,28 & 615,76 & 620,61 & 620,06 & 588,34 \\
\hline 19 & 795,95 & 618,65 & 610,91 & 626,34 & 573,96 \\
\hline 20 & 801,49 & 633,71 & 626,46 & 651,07 & 576,83 \\
\hline 21 & 885,98 & 652,71 & 709,45 & 700,09 & 650,33 \\
\hline 22 & 837,97 & 656,55 & 698,89 & 681,87 & 679,29 \\
\hline 23 & 853,60 & 669,23 & 683,37 & 708,58 & 690,38 \\
\hline 24 & 750,14 & 571,75 & 606,69 & 579,79 & 575,81 \\
\hline 25 & 863,98 & 633,34 & 671,89 & 631,33 & 644,75 \\
\hline 26 & 768,32 & 610,90 & 588,73 & 578,27 & 584,48 \\
\hline 27 & 797,51 & 615,85 & 620,40 & 475,42 & 621,49 \\
\hline 28 & 794,59 & 655,53 & 627,94 & 644,47 & 622,09 \\
\hline 29 & 797,92 & 650,72 & 621,14 & 645,43 & 600,40 \\
\hline 30 & 834,99 & 645,91 & 608,78 & 621,90 & 374,58 \\
\hline 31 & 746,56 & 579,46 & 620,94 & 621,83 & 586,87 \\
\hline 32 & 837,48 & 662,13 & 699,93 & 676,53 & 668,87 \\
\hline 33 & 841,27 & 651,44 & 717,39 & 664,98 & 662,60 \\
\hline 34 & 857,33 & 689,53 & 755,20 & 689,83 & 674,25 \\
\hline 35 & 821,64 & 653,49 & 699,10 & 645,68 & 660,18 \\
\hline 36 & 837,11 & 687,77 & 704,68 & 700,79 & 652,72 \\
\hline
\end{tabular}


Continuação

\begin{tabular}{|c|c|c|c|c|c|}
\hline $\begin{array}{l}\text { Irradiação } \\
\text { Dosímetro }\end{array}$ & 1 & 2 & 3 & 4 & 5 \\
\hline 37 & 755,48 & 631,31 & 621,08 & 614,77 & 592,15 \\
\hline 38 & 825,58 & 687,70 & 646,70 & 641,83 & 602,48 \\
\hline 39 & 891,22 & 706,74 & 633,93 & 681,37 & 591,76 \\
\hline 40 & 741,09 & 603,18 & 546,50 & 548,08 & 522,80 \\
\hline 41 & 751,11 & 567,03 & 601,06 & 578,87 & 583,72 \\
\hline 42 & 778,83 & 571,53 & 607,31 & 580,39 & 606,66 \\
\hline 43 & 813,67 & 635,20 & 644,16 & 653,92 & 657,72 \\
\hline 44 & 923,36 & 642,63 & 679,33 & 635,48 & 662,90 \\
\hline 45 & 834,43 & 680,67 & 695,52 & 679,95 & 645,11 \\
\hline 46 & 845,79 & 676,08 & 683,17 & 707,39 & 672,30 \\
\hline 47 & 887,66 & 735,70 & 709,35 & 710,66 & 698,02 \\
\hline 48 & 820,09 & 685,26 & 669,74 & 669,01 & 647,43 \\
\hline 49 & 1068,29 & 872,97 & 832,09 & 834,17 & 722,93 \\
\hline 50 & 783,08 & 678,23 & 651,57 & 646,80 & 603,64 \\
\hline 51 & 1082,92 & 829,20 & 863,46 & 842,99 & 748,50 \\
\hline 52 & 1013,26 & 775,32 & 821,00 & 789,82 & 728,03 \\
\hline 53 & 1024,48 & 792,39 & 847,13 & 824,26 & 760,72 \\
\hline 54 & 1091,93 & 859,55 & 906,84 & 859,04 & 751,68 \\
\hline 55 & 1093,37 & 873,47 & 924,47 & 865,83 & 747,25 \\
\hline 56 & 1085,21 & 881,16 & 889,39 & 842,06 & 743,19 \\
\hline 57 & 1013,24 & 803,76 & 790,98 & 787,62 & 742,22 \\
\hline 58 & 1025,31 & 837,56 & 805,08 & 808,35 & 718,93 \\
\hline 59 & 1026,87 & 837,98 & 788,34 & 807,56 & 727,49 \\
\hline 60 & 933,46 & 752,68 & 710,25 & 735,80 & 666,50 \\
\hline 61 & 971,99 & 760,31 & 784,86 & 767,21 & 692,82 \\
\hline 62 & 950,99 & 737,45 & 769,37 & 821,84 & 716,08 \\
\hline 63 & 1057,69 & 803,25 & 858,84 & 792,71 & 743,99 \\
\hline 64 & 1020,01 & 810,65 & 854,87 & 856,58 & 734,59 \\
\hline 65 & 1074,99 & 810,70 & 813,22 & 822,85 & 730,73 \\
\hline 66 & 1037,58 & 836,36 & 776,05 & 823,68 & 733,67 \\
\hline 67 & 915,30 & 759,49 & 712,89 & 727,96 & 695,79 \\
\hline 68 & 1032,11 & 878,77 & 810,65 & 832,22 & 674,32 \\
\hline 69 & 936,70 & 772,38 & 749,38 & 736,67 & 631,86 \\
\hline 70 & 1054,80 & 898,21 & 782,13 & 845,99 & 711,38 \\
\hline 71 & 1026,30 & 784,19 & 774,80 & 809,24 & 731,87 \\
\hline 72 & 1040,03 & 801,78 & 809,61 & 796,22 & 723,54 \\
\hline 73 & 1087,97 & 789,92 & 835,02 & 815,28 & 727,29 \\
\hline 74 & 1021,86 & 797,16 & 826,30 & 843,33 & 715,29 \\
\hline 75 & 752,87 & 606,11 & 604,08 & 606,28 & 602,44 \\
\hline 76 & 660,83 & 549,54 & 527,66 & 551,76 & 555,85 \\
\hline 77 & 605,42 & 508,24 & 497,25 & 515,38 & 523,85 \\
\hline
\end{tabular}


Continuação

\begin{tabular}{|c|c|c|c|c|c|}
\hline $\begin{array}{l}\text { Irradiação } \\
\text { Dosímetro }\end{array}$ & 1 & 2 & 3 & 4 & 5 \\
\hline 78 & 686,78 & 594,80 & 533,83 & 551,37 & 549,18 \\
\hline 79 & 658,79 & 544,90 & 558,01 & 529,52 & 517,14 \\
\hline 80 & 1064,04 & 854,69 & 846,63 & 833,52 & 737,44 \\
\hline 81 & 1023,91 & 778,79 & 788,48 & 833,25 & 733,81 \\
\hline 82 & 942,54 & 727,81 & 747,04 & 765,08 & 713,76 \\
\hline 83 & 1053,15 & 812,08 & 831,40 & 859,38 & 724,01 \\
\hline 84 & 1044,59 & 802,84 & 896,52 & 866,17 & 762,12 \\
\hline 85 & 1098,23 & 838,95 & 912,52 & 908,18 & 322,83 \\
\hline 86 & 1035,14 & 827,01 & 804,92 & 848,97 & 732,36 \\
\hline 87 & 995,73 & 802,61 & 825,20 & 818,49 & 715,59 \\
\hline 88 & 973,29 & 770,96 & 781,62 & 799,11 & 371,61 \\
\hline 89 & 1057,08 & 842,02 & 827,38 & 832,88 & 665,65 \\
\hline 90 & 1079,71 & 818,94 & 811,17 & 841,49 & 727,80 \\
\hline 91 & 966,88 & 791,65 & 805,79 & 815,54 & 728,45 \\
\hline 92 & 991,10 & 790,09 & 794,65 & 804,61 & 724,70 \\
\hline 93 & 936,98 & 780,37 & 741,48 & 791,63 & 710,99 \\
\hline 94 & 984,57 & 805,20 & 819,34 & 838,48 & 722,02 \\
\hline 95 & 1027,96 & 807,92 & 846,20 & 821,57 & 730,80 \\
\hline 96 & 961,35 & 804,25 & 802,19 & 816,31 & 714,40 \\
\hline 97 & 1010,20 & 847,51 & 805,14 & 864,32 & 726,07 \\
\hline 98 & 987,57 & 792,52 & 813,24 & 778,27 & 731,73 \\
\hline 99 & 1005,21 & 832,02 & 794,23 & 821,81 & 725,16 \\
\hline 100 & 972,66 & 808,96 & 758,83 & 783,65 & 717,00 \\
\hline
\end{tabular}




\section{APÊNDICE 07}

Tabela - Teste de homogeneidade do grupo de cem dosímetros a partir do valor da área do pico principal $\left(A_{p p}\right)$ da emissão TL após a deconvolução.

\begin{tabular}{|c|c|c|c|c|c|}
\hline $\begin{array}{l}\text { Irradiação } \\
\text { Dosímetro }\end{array}$ & 1 & 2 & 3 & 4 & 5 \\
\hline 1 & 632,14 & 509,48 & 515,77 & 533,84 & 301,18 \\
\hline 2 & 593,72 & 474,18 & 498,51 & 476,60 & 284,12 \\
\hline 3 & 610,97 & 533,44 & 561,47 & 531,15 & 322,26 \\
\hline 4 & 760,89 & 632,91 & 657,34 & 625,74 & 380,75 \\
\hline 5 & 647,50 & 546,48 & 562,19 & 526,53 & 313,76 \\
\hline 6 & 603,53 & 523,07 & 519,20 & 501,38 & 314,75 \\
\hline 7 & 562,43 & 510,56 & 509,62 & 506,29 & 310,81 \\
\hline 8 & 591,89 & 533,34 & 531,03 & 510,75 & 309,49 \\
\hline 9 & 507,05 & 485,16 & 448,25 & 438,72 & 282,08 \\
\hline 10 & 536,94 & 496,55 & 466,77 & 524,53 & 293,81 \\
\hline 11 & 657,92 & 518,60 & 553,80 & 530,67 & 315,60 \\
\hline 12 & 543,17 & 482,41 & 517,09 & 499,75 & 270,08 \\
\hline 13 & 607,58 & 457,68 & 507,96 & 484,50 & 300,32 \\
\hline 14 & 584,02 & 496,38 & 507,42 & 492,42 & 293,11 \\
\hline 15 & 569,84 & 544,26 & 501,88 & 477,05 & 311,17 \\
\hline 16 & 527,85 & 487,85 & 492,23 & 476,24 & 296,05 \\
\hline 17 & 594,53 & 542,36 & 564,72 & 570,49 & 323,34 \\
\hline 18 & 569,18 & 526,60 & 538,58 & 518,84 & 310,98 \\
\hline 19 & 595,94 & 599,20 & 517,68 & 537,06 & 269,14 \\
\hline 20 & 583,97 & 560,72 & 528,37 & 537,65 & 271,81 \\
\hline 21 & 691,55 & 550,89 & 601,49 & 581,89 & 327,21 \\
\hline 22 & 607,99 & 562,74 & 584,67 & 576,37 & 361,93 \\
\hline 23 & 617,45 & 553,32 & 629,34 & 574,48 & 364,12 \\
\hline 24 & 541,00 & 490,58 & 518,54 & 480,81 & 290,70 \\
\hline 25 & 702,07 & 549,03 & 571,32 & 539,76 & 336,75 \\
\hline 26 & 603,40 & 517,79 & 507,07 & 475,43 & 290,18 \\
\hline 27 & 582,00 & 524,07 & 532,70 & 434,79 & 318,86 \\
\hline 28 & 593,17 & 579,14 & 536,93 & 527,88 & 323,50 \\
\hline 29 & 582,83 & 550,26 & 535,43 & 533,42 & 323,91 \\
\hline 30 & 607,60 & 555,86 & 515,31 & 534,60 & 371,65 \\
\hline 31 & 547,33 & 479,91 & 541,02 & 523,62 & 301,62 \\
\hline 32 & 656,33 & 561,76 & 597,21 & 557,56 & 357,96 \\
\hline 33 & 651,22 & 546,93 & 608,02 & 550,53 & 337,56 \\
\hline 34 & 657,51 & 596,39 & 651,70 & 558,44 & 352,93 \\
\hline 35 & 645,09 & 548,42 & 602,05 & 545,78 & 346,61 \\
\hline 36 & 619,50 & 590,71 & 614,31 & 589,29 & 339,39 \\
\hline 37 & 615,49 & 537,30 & 539,58 & 501,19 & 318,19 \\
\hline
\end{tabular}


Continuação

\begin{tabular}{|c|c|c|c|c|c|}
\hline $\begin{array}{l}\text { Irradiação } \\
\text { Dosímetro }\end{array}$ & 1 & 2 & 3 & 4 & 5 \\
\hline 38 & 605,67 & 588,21 & 561,33 & 527,79 & 300,67 \\
\hline 39 & 723,53 & 570,26 & 527,98 & 559,25 & 287,11 \\
\hline 40 & 581,14 & 496,22 & 465,90 & 479,49 & 276,78 \\
\hline 41 & 557,45 & 483,98 & 522,58 & 494,31 & 293,78 \\
\hline 42 & 611,24 & 473,97 & 520,41 & 495,52 & 314,41 \\
\hline 43 & 607,08 & 560,40 & 578,39 & 552,60 & 345,78 \\
\hline 44 & 744,19 & 553,37 & 579,16 & 535,50 & 341,66 \\
\hline 45 & 661,85 & 590,38 & 580,43 & 575,25 & 328,47 \\
\hline 46 & 669,77 & 580,55 & 588,04 & 591,33 & 356,88 \\
\hline 47 & 689,96 & 629,05 & 613,93 & 601,37 & 375,52 \\
\hline 48 & 638,04 & 599,81 & 578,59 & 545,93 & 341,22 \\
\hline 49 & 800,97 & 741,23 & 729,83 & 692,50 & 392,67 \\
\hline 50 & 734,01 & 576,47 & 561,82 & 548,97 & 302,46 \\
\hline 51 & 919,21 & 711,23 & 733,78 & 712,88 & 392,67 \\
\hline 52 & 846,24 & 682,63 & 709,18 & 677,39 & 392,67 \\
\hline 53 & 812,62 & 671,79 & 737,01 & 684,15 & 392,67 \\
\hline 54 & 853,26 & 759,51 & 777,05 & 726,21 & 392,67 \\
\hline 55 & 857,57 & 753,81 & 809,47 & 706,40 & 392,98 \\
\hline 56 & 839,84 & 770,13 & 827,03 & 716,77 & 392,67 \\
\hline 57 & 776,36 & 683,70 & 674,03 & 674,48 & 392,67 \\
\hline 58 & 783,55 & 742,59 & 695,37 & 670,72 & 392,67 \\
\hline 59 & 813,27 & 708,02 & 692,58 & 684,14 & 395,59 \\
\hline 60 & 743,21 & 681,60 & 603,84 & 643,87 & 341,17 \\
\hline 61 & 782,89 & 647,11 & 687,40 & 657,54 & 374,22 \\
\hline 62 & 760,76 & 641,03 & 667,38 & 665,00 & 383,73 \\
\hline 63 & 826,80 & 678,46 & 754,70 & 684,32 & 392,47 \\
\hline 64 & 832,07 & 719,59 & 739,06 & 702,90 & 392,67 \\
\hline 65 & 828,68 & 710,27 & 714,99 & 710,96 & 394,86 \\
\hline 66 & 840,41 & 711,00 & 694,50 & 678,09 & 392,67 \\
\hline 67 & 730,51 & 649,03 & 616,67 & 615,21 & 381,16 \\
\hline 68 & 837,85 & 775,01 & 710,95 & 721,21 & 400,31 \\
\hline 69 & 758,24 & 671,04 & 654,10 & 647,30 & 372,48 \\
\hline 70 & 801,32 & 754,59 & 727,21 & 771,65 & 386,68 \\
\hline 71 & 809,75 & 664,82 & 666,32 & 690,02 & 392,67 \\
\hline 72 & 810,76 & 669,25 & 707,54 & 667,69 & 392,67 \\
\hline 73 & 881,64 & 669,02 & 719,25 & 685,37 & 392,67 \\
\hline 74 & 790,83 & 694,63 & 724,37 & 722,69 & 392,67 \\
\hline 75 & 588,66 & 518,36 & 504,96 & 516,75 & 306,92 \\
\hline 76 & 468,80 & 462,27 & 431,31 & 429,21 & 287,19 \\
\hline 77 & 455,63 & 437,08 & 408,85 & 427,54 & 235,29 \\
\hline 78 & 521,12 & 481,20 & 435,43 & 448,16 & 326,97 \\
\hline 79 & 528,03 & 440,47 & 470,95 & 407,36 & 268,44 \\
\hline
\end{tabular}


Continuação

\begin{tabular}{|c|c|c|c|c|c|}
\hline $\begin{array}{l}\text { Irradiação } \\
\text { Dosímetro }\end{array}$ & 1 & 2 & 3 & 4 & 5 \\
\hline 80 & 833,15 & 742,17 & 725,51 & 729,21 & 392,67 \\
\hline 81 & 874,60 & 684,27 & 703,28 & 717,79 & 392,67 \\
\hline 82 & 799,07 & 615,93 & 658,91 & 671,53 & 391,66 \\
\hline 83 & 899,44 & 683,85 & 720,16 & 748,17 & 401,22 \\
\hline 84 & 819,93 & 680,36 & 751,17 & 718,15 & 395,36 \\
\hline 85 & 740,25 & 767,12 & 767,15 & 756,31 & 322,83 \\
\hline 86 & 836,71 & 712,15 & 692,09 & 720,68 & 392,67 \\
\hline 87 & 797,21 & 693,29 & 723,72 & 700,98 & 392,67 \\
\hline 88 & 792,72 & 673,61 & 687,05 & 697,28 & 243,92 \\
\hline 89 & 803,48 & 739,66 & 704,76 & 706,93 & 393,92 \\
\hline 90 & 883,36 & 702,60 & 705,21 & 734,45 & 392,67 \\
\hline 91 & 820,12 & 656,04 & 711,38 & 689,48 & 392,67 \\
\hline 92 & 828,36 & 664,88 & 667,86 & 677,88 & 392,67 \\
\hline 93 & 794,56 & 659,02 & 702,80 & 688,80 & 392,67 \\
\hline 94 & 826,02 & 695,32 & 693,30 & 743,49 & 392,67 \\
\hline 95 & 859,78 & 744,02 & 720,78 & 727,96 & 392,67 \\
\hline 96 & 823,88 & 706,02 & 675,75 & 692,09 & 413,54 \\
\hline 97 & 860,57 & 739,53 & 742,69 & 731,00 & 392,67 \\
\hline 98 & 834,13 & 735,47 & 706,40 & 730,61 & 394,83 \\
\hline 99 & 857,27 & 721,16 & 742,44 & 691,41 & 394,13 \\
\hline 100 & 798,77 & 689,35 & 640,00 & 693,18 & 392,67 \\
\hline
\end{tabular}




\section{APÊNDICE 08}

Tabela -Análise estatística dos dados apresentados na tabela do apêndice 05 para o cálculo do Índice de Variabilidade do Sistema (SVI).

\begin{tabular}{cccc}
\hline Dosímetro & $\overline{\mathrm{M}}$ & $\sigma_{L}$ & $\mathrm{CV}$ \\
\hline 1 & 1,196 & 0,077 & 0,064 \\
2 & 1,193 & 0,038 & 0,032 \\
3 & 1,301 & 0,300 & 0,230 \\
4 & 1,488 & 0,292 & 0,196 \\
5 & 1,316 & 0,243 & 0,185 \\
6 & 1,395 & 0,289 & 0,207 \\
7 & 1,390 & 0,241 & 0,173 \\
8 & 1,506 & 0,348 & 0,231 \\
9 & 1,358 & 0,368 & 0,271 \\
10 & 1,449 & 0,239 & 0,165 \\
11 & 1,240 & 0,123 & 0,099 \\
12 & 1,409 & 0,314 & 0,223 \\
13 & 1,333 & 0,273 & 0,205 \\
14 & 1,291 & 0,199 & 0,154 \\
15 & 1,294 & 0,243 & 0,188 \\
16 & 1,455 & 0,324 & 0,222 \\
17 & 1,403 & 0,366 & 0,261 \\
18 & 1,498 & 0,354 & 0,236 \\
19 & 1,462 & 0,344 & 0,235 \\
20 & 1,430 & 0,336 & 0,235 \\
21 & 1,341 & 0,350 & 0,261 \\
22 & 1,315 & 0,199 & 0,151 \\
23 & 1,484 & 0,279 & 0,188 \\
24 & 1,316 & 0,197 & 0,150 \\
25 & 1,366 & 0,287 & 0,210 \\
26 & 1,316 & 0,196 & 0,149 \\
27 & 1,386 & 0,295 & 0,213 \\
28 & 1,414 & 0,333 & 0,235 \\
29 & 1,540 & 0,341 & 0,222 \\
30 & 1,423 & 0,337 & 0,237 \\
31 & 1,319 & 0,312 & 0,237 \\
32 & 1,351 & 0,239 & 0,177 \\
33 & 1,268 & 0,126 & 0,099 \\
34 & 1,404 & 0,227 & 0,161 \\
35 & 1,215 & 0,146 & 0,120 \\
36 & 1,359 & 0,320 & 0,236 \\
37 & 1,304 & 0,071 & 0,055 \\
\hline & Continua & \\
& & &
\end{tabular}


Continuação

\begin{tabular}{cccc}
\hline Dosímetro & $\overline{\mathrm{M}}$ & $\sigma_{L}$ & $\mathrm{CV}$ \\
\hline 38 & 1,525 & 0,341 & 0,223 \\
39 & 1,353 & 0,164 & 0,121 \\
40 & 1,275 & 0,315 & 0,247 \\
41 & 1,429 & 0,336 & 0,235 \\
42 & 1,296 & 0,303 & 0,234 \\
43 & 1,251 & 0,183 & 0,146 \\
44 & 1,388 & 0,356 & 0,257 \\
45 & 1,267 & 0,126 & 0,100 \\
46 & 1,494 & 0,230 & 0,154 \\
47 & 1,254 & 0,165 & 0,132 \\
48 & 1,466 & 0,343 & 0,234 \\
49 & 1,364 & 0,282 & 0,207 \\
50 & 1,423 & 0,212 & 0,149 \\
51 & 1,498 & 0,412 & 0,275 \\
52 & 1,569 & 0,278 & 0,177 \\
53 & 1,440 & 0,363 & 0,252 \\
54 & 1,551 & 0,295 & 0,190 \\
55 & 1,334 & 0,232 & 0,174 \\
56 & 1,431 & 0,297 & 0,208 \\
57 & 1,423 & 0,288 & 0,202 \\
58 & 1,488 & 0,322 & 0,216 \\
59 & 1,499 & 0,256 & 0,170 \\
60 & 1,403 & 0,236 & 0,169 \\
61 & 1,520 & 0,356 & 0,234 \\
62 & 1,481 & 0,285 & 0,193 \\
63 & 1,459 & 0,232 & 0,159 \\
64 & 1,427 & 0,349 & 0,244 \\
65 & 1,307 & 0,273 & 0,209 \\
66 & 1,440 & 0,342 & 0,237 \\
67 & 1,385 & 0,312 & 0,225 \\
68 & 1,423 & 0,208 & 0,146 \\
69 & 1,364 & 0,243 & 0,178 \\
70 & 1,503 & 0,298 & 0,198 \\
71 & 1,619 & 0,307 & 0,189 \\
72 & 1,517 & 0,253 & 0,167 \\
73 & 1,520 & 0,348 & 0,229 \\
74 & 1,309 & 0,298 & 0,228 \\
75 & 1,209 & 0,135 & 0,111 \\
76 & 1,435 & 0,365 & 0,254 \\
77 & 1,355 & 0,308 & 0,227 \\
& 1,286 & 0,231 & 0,179 \\
& 1,293 & 0,199 & 0,154 \\
\hline 7 & Continua & \\
79 & &
\end{tabular}


Continuação

\begin{tabular}{cccc}
\hline Dosímetro & $\overline{\mathrm{M}}$ & $\sigma_{L}$ & $\mathrm{CV}$ \\
\hline 80 & 1,512 & 0,346 & 0,229 \\
81 & 1,367 & 0,308 & 0,225 \\
82 & 1,495 & 0,314 & 0,210 \\
83 & 1,501 & 0,271 & 0,180 \\
84 & 1,503 & 0,416 & 0,277 \\
85 & 1,547 & 0,288 & 0,186 \\
86 & 1,515 & 0,282 & 0,186 \\
87 & 1,378 & 0,340 & 0,247 \\
88 & 1,481 & 0,164 & 0,111 \\
89 & 1,502 & 0,326 & 0,217 \\
90 & 1,462 & 0,304 & 0,208 \\
91 & 1,546 & 0,259 & 0,168 \\
92 & 1,573 & 0,281 & 0,179 \\
93 & 1,433 & 0,275 & 0,192 \\
94 & 1,626 & 0,305 & 0,187 \\
95 & 1,550 & 0,284 & 0,183 \\
96 & 1,440 & 0,356 & 0,247 \\
97 & 1,624 & 0,299 & 0,184 \\
98 & 1,604 & 0,294 & 0,183 \\
99 & 1,548 & 0,261 & 0,169 \\
100 & 1,509 & 0,243 & 0,161 \\
\hline
\end{tabular}

